\title{
Mesoporous $\mathrm{MnCo}_{2} \mathrm{O}_{4}, \mathrm{NiCO}_{2} \mathrm{O}_{4}$, and $\mathrm{ZnCo}_{2} \mathrm{O}_{4}$ Thin-Film Electrodes as Electrocatalysts for the Oxygen Evolution Reaction in Alkaline Solutions
}

\author{
Assel Amirzhanova, Nesibe Akmanşen, Irmak Karakaya, and Ömer Dag* \\ Cite This: ACS Appl. Energy Mater. 2021, 4, 2769-2785 \\ Read Online
}

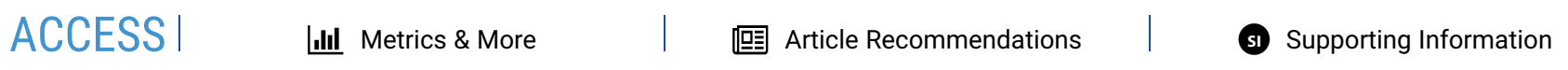

ABSTRACT: The oxygen evolution reaction (OER) is the bottleneck of the electrochemical water-splitting process, where the use of porous metal oxide electrodes is beneficial. In this work, we introduce a one-pot synthesis method to fabricate a series of mesoporous metal cobaltite $\left(\mathrm{m}-\mathrm{MCo}_{2} \mathrm{O}_{4}, \mathrm{M}=\mathrm{Mn}, \mathrm{Ni}\right.$, and $\left.\mathrm{Zn}\right)$ electrodes for the OER. The method involves preparation and coating of a homogeneous clear solution of all ingredients (metal salts and surfactants) over a fluorine-doped tin oxide surface as a thin lyotropic liquid crystalline film and calcination (as low as $250{ }^{\circ} \mathrm{C}$ ) to obtain a $400 \mathrm{~nm}$ thick crystalline $\mathrm{m}-\mathrm{MCo}_{2} \mathrm{O}_{4}$ electrode with a spinel structure. Mesophases and $\mathrm{m}-\mathrm{MCo}_{2} \mathrm{O}_{4}$ films are characterized using structural and electrochemical techniques. All electrodes are stable during the electrochemical test in $1 \mathrm{M} \mathrm{KOH}$ aqueous solution and perform at as low as $204 \mathrm{mV}$ overpotential at $1 \mathrm{~mA} / \mathrm{cm}^{2}$ current density; the $\mathrm{m}-\mathrm{MnCo}_{2} \mathrm{O}_{4}$ electrode works at current densities of 1,10 , and $100 \mathrm{~mA} / \mathrm{cm}^{2}$ at 227,300 , and 383

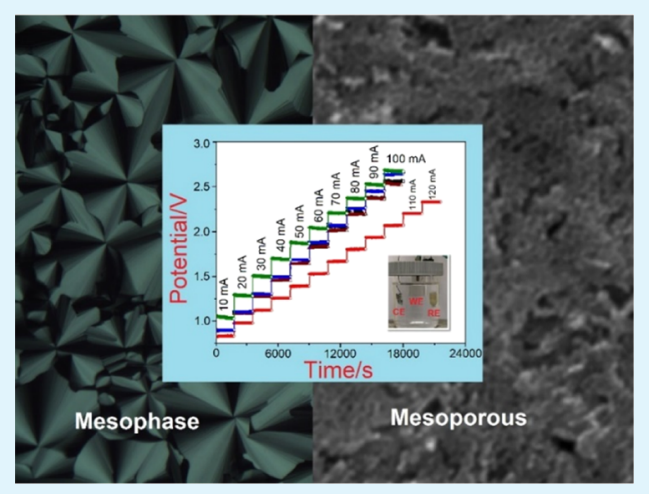
$\mathrm{mV}$ overpotentials after compensating the IR drop, respectively. The Tafel slope is $60 \mathrm{mV} / \mathrm{dec}$ for the $\mathrm{m}-\mathrm{NiCo}_{2} \mathrm{O}_{4}$ and $\mathrm{m}-\mathrm{ZnCo}_{2} \mathrm{O}_{4}$ electrodes, but it gradually increases to $85 \mathrm{mV} / \mathrm{dec}$ in the $\mathrm{m}-\mathrm{MnCo}_{2} \mathrm{O}_{4}$ electrode by thermal treatment, indicating a change in the OER mechanism.

KEYWORDS: molten salt-assisted self-assembly, metal cobaltites, mesoporous materials, electrocatalysis, oxygen evolution reaction

\section{INTRODUCTION}

Mesoporous and nanoscaled metal oxides, metal sulfides, carbon, metal-organic frameworks, and phosphates are important materials in the production and storage of clean energy. ${ }^{1-13}$ Especially, mesoporous spinel oxides have been widely investigated for water oxidation electrocatalysis. ${ }^{14-22}$ Transition-metal cobaltites $\left(\mathrm{MCo}_{2} \mathrm{O}_{4}\right)$ are employed as efficient electrocatalysts for water oxidation and as electrodes in supercapacitors and batteries; ${ }^{17-22}$ therefore, many strategies have been developed to synthesize these materials. ${ }^{23,24}$ Most methods produce powder samples that require further fabrication steps and special chemicals to build into electrodes. Designing synthetic strategies that involve one-pot, single-step film fabrication would help to enable the development of these electrodes for practical use. Manganese, nickel, and zinc cobaltites have special significance due to the abundance of $\mathrm{Mn}, \mathrm{Ni}$, and $\mathrm{Zn}$ in the earth's crust, and they are used as stable electrodes in many applications. For instance, mesoporous $\mathrm{MnCo}_{2} \mathrm{O}_{4}$ has been successfully employed for both the oxygen evolution reaction (OER) and oxygen reduction reaction. ${ }^{17}$ $\mathrm{NiCo}_{2} \mathrm{O}_{4}$ displays good OER performance at relatively low overpotential values ${ }^{18}$ and is a good candidate for supercapacitors. ${ }^{19}$ Similarly, $\mathrm{ZnCo}_{2} \mathrm{O}_{4}$ displays high electrochemical activity/stability in energy-storage applications as a capacitor ${ }^{20}$ and lithium-oxygen batteries in addition to the OER-active electrode material. ${ }^{21,22}$

Several methods have been developed to synthesize mesoporous transition-metal oxides and mixed oxides. These methods can be divided into two main categories; hard and soft templating. $^{25-39}$ Hard-templating methods produce ordered mesoporous powders but require multiple tedious steps. ${ }^{25-29}$ Soft-templating methods involve surfactants and self-assembly processes in both the solution phase ${ }^{30-32}$ and lyotropic liquid crystalline mesophase (LLCM). ${ }^{33-39}$ Solution-phase synthesis is less successful and produces powders; however, LLCMmediated synthesis is quite successful in producing metal oxides as thin films and monoliths. ${ }^{33-39}$ LLCM-mediated synthesis can be employed by either using a polymerizing agent [such as tetramethylorthosilicate, $\mathrm{Si}\left(\mathrm{OCH}_{3}\right)_{4}$, or titanium tetrabutoxide, $\left.\mathrm{Ti}\left(\mathrm{OC}_{4} \mathrm{H}_{9}\right)_{4}\right]$ and a transition-metal salt ${ }^{33-35}$ or directly using only transition-metal salts. ${ }^{36-39}$ The formation of a salt-

Received: January 7, 2021

Accepted: February 10, 2021

Published: February 18, 2021

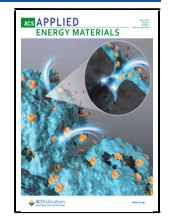


Scheme 1. Outline of the Work

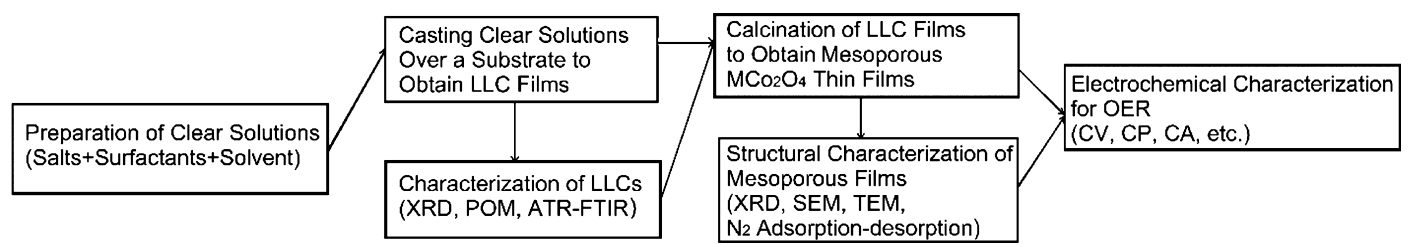

surfactant LLCMs was introduced nearly 20 years ago. ${ }^{40}$ Simply, salt species are in the molten phase in the hydrophilic domains of the LLCM, where the molten salt behaves as a solvent. ${ }^{41}$ The addition of a second salt ${ }^{36-39}$ or a charged surfactant ${ }^{42}$ stabilizes the lyotropic liquid crystalline (LLC) phase at much higher salt concentrations and can be used in further steps to produce mesoporous metal oxides. This method is known as the molten salt-assisted self-assembly (MASA) process. ${ }^{34}$ The first step of this assembly process is the preparation of a clear homogeneous solution that consists of salts and surfactants together with a volatile solvent (water or ethanol). Coating (spin, deep, or spray) or casting of the clear solution produces thin and thick gel LLCMs by evaporating the volatile solvent. Since the salt concentration of the LLCMs are high (in some cases, over $80 \mathrm{w}$ / $\mathrm{w} \%$ salt to surfactant), one must be careful in preparing the clear solutions and in the coating steps that may lead to salt crystallization. Note that the salt crystals, embedded in the LLCM, produce their bulk metal oxides upon calcination and the oxide impurities in mixed oxides. ${ }^{37,39}$ However, the LLCMs without salt-crystallization yield homogeneous mesoporous films or monoliths upon calcination over $300{ }^{\circ} \mathrm{C}$. The resulting porous materials have two pore systems; the small pores form due to surfactant domains in the LLCM and the large pores form due to the evolution of gaseous products of salt species, water, and surfactant during calcination and/or collapse of the small pores in favor of large ones. Therefore, the resulting structures have ideal pore systems and are beneficial in catalytic applications. $^{36-39}$

The MASA method has already been used to produce electrodes for the OER, such as $\mathrm{LiCoO}_{2}{ }^{36} \mathrm{LiMn}_{2-x} \mathrm{Co}_{x} \mathrm{O}_{4},{ }^{37,39}$ and $\mathrm{NiO}^{38}$ as thin-film electrodes. Thin films have uniform twopore systems which make them highly active as electrocatalysts for the OER. The lithium and metal salts and two transitionmetal salts synergistically affect each other in the mesophase, each enhancing the solubility of the other, lowering their melting points, and hindering the crystallization of the salt species to stabilize the LLCMs. This work (as outlined in Scheme 1) is the first example of the use of two transition-metal salts without lithium salt in the mesophase. We investigate $\mathrm{Mn}(\mathrm{II}) / \mathrm{Co}$ (II), $\mathrm{Ni}(\mathrm{II}) / \mathrm{Co}(\mathrm{II})$, and $\mathrm{Zn}(\mathrm{II}) / \mathrm{Co}(\mathrm{II})$ salt couples as examples of two salt systems that can be used to produce mesoporous thin films of $\mathrm{MnCo}_{2} \mathrm{O}_{4}, \mathrm{NiCo}_{2} \mathrm{O}_{4}$, and $\mathrm{ZnCo}_{2} \mathrm{O}_{4}$, respectively. The mesophases and thin films were characterized using common techniques [such as X-ray diffraction (XRD), attenuated total reflectance-Fourier transform infrared (ATR-FTIR), X-ray photoelectron spectroscopy (XPS), polarized optical microscopy (POM), scanning electron microscopy (SEM), transmission electron microscopy (TEM), $\mathrm{N}_{2}$ adsorption-desorption isotherms] and their electrochemical properties were characterized using a three-electrode system toward OER.

\section{EXPERIMENTAL PART}

Preparation of $M($ II)/Co(II) Solutions. $M($ II) $/ \mathrm{Co}(\mathrm{II})(\mathrm{M}$ is $\mathrm{Ni}$ and $\mathrm{Mn}$ ) solutions were prepared at different total salt $[\mathrm{M}(\mathrm{II})$ plus
$\mathrm{Co}(\mathrm{II})]$ to surfactant mole ratios, from 6 to 25 . All metal salts are aqua complexes of nitrate salts $\left(\left[\mathrm{M}\left(\mathrm{H}_{2} \mathrm{O}\right)_{\mathrm{n}}\right]\left(\mathrm{NO}_{3}\right)_{2}\right)$. The nickel (or manganese) to cobalt salt mole ratio was kept as 1:2 to make sure that the calcination product is a pure spinel structure of $\mathrm{MCo}_{2} \mathrm{O}_{4}$. The concentrations of cetyl trimethyl ammonium bromide (CTAB) and $\mathrm{C}_{12} \mathrm{H}_{25}\left(\mathrm{OCH}_{2} \mathrm{CH}_{2}\right)_{10} \mathrm{OH}\left(\mathrm{C}_{12} \mathrm{E}_{10}\right)$ were kept constant at 1:1 mole ratio in all solutions and were used at amounts of 0.291 and $0.500 \mathrm{~g}$, respectively. Ethanol was used as a primary solvent to homogenize the mixtures. Higher salt ratios required more ethanol to obtain clear solutions. Thus, from 6 to 12 salt to surfactant mole ratios, the amount of ethanol used to homogenize the mixtures was $5 \mathrm{~mL}$ and from 15 to 25 salt to surfactant mole ratios, $10 \mathrm{~mL}$ of ethanol was used.

A typical solution preparation is as follows: for example, for the 6 mole ratio of nickel solution, first $0.464 \mathrm{~g}$ of $\left[\mathrm{Ni}\left(\mathrm{H}_{2} \mathrm{O}\right)_{6}\right]\left(\mathrm{NO}_{3}\right)_{2}, 0.929$ $\mathrm{g}$ of $\left[\mathrm{Co}\left(\mathrm{H}_{2} \mathrm{O}\right)_{6}\right]\left(\mathrm{NO}_{3}\right)_{2}, 0.291 \mathrm{~g}_{\text {of }} \mathrm{C}_{16} \mathrm{H}_{33} \mathrm{~N}\left(\mathrm{CH}_{3}\right)_{3} \mathrm{Br}(\mathrm{CTAB})$, and 5 $\mathrm{mL}$ of ethanol were added into a vial and stirred for 15 min using a magnetic stirrer to obtain a clear solution. Then, $0.500 \mathrm{~g}$ of a non-ionic surfactant $\left(\mathrm{C}_{12} \mathrm{E}_{10}\right)$ was added to the clear solution and stirred for another $30 \mathrm{~min}$ to obtain a final clear and homogeneous solution. Accordingly, the amount of $\mathrm{Ni}(\mathrm{II})$ and $\mathrm{Co}(\mathrm{II})$ added was changed; for the other solutions, see Table S1. The same procedure was used to prepare all other solutions.

For $\mathrm{Zn}(\mathrm{II}) / \mathrm{Co}(\mathrm{II})$ solutions, P123 $\mathrm{H}-\left(\mathrm{OCH}_{2} \mathrm{CH}_{2}\right)_{20}-$ $\left.\left(\mathrm{OCH}_{2} \mathrm{CH}\left(\mathrm{CH}_{3}\right)\right)_{70}-\left(\mathrm{OCH}_{2} \mathrm{CH}_{2}\right)_{20}-\mathrm{OH}\right]$ has been used with a slight modification of the above procedure. For preparing a 20:40:5:1 [Zn(II):Co(II):CTAB:P123 mole ratio] solution: $1.0 \mathrm{~g}$ of P123 was added to $5.0 \mathrm{~mL}$ of deionized water in a $25 \mathrm{~mL}$ glass vial and the mixture was stirred with a magnetic stirrer overnight to obtain a clear solution. Then, $0.314 \mathrm{~g}$ of $\mathrm{CTAB}$ was added to the clear solution and stirred until it became clear. Finally, $1.024 \mathrm{~g}$ of $\left[\mathrm{Zn}\left(\mathrm{H}_{2} \mathrm{O}\right)_{6}\right]\left(\mathrm{NO}_{3}\right)_{2}$ and $2.000 \mathrm{~g}$ of $\left[\mathrm{Co}\left(\mathrm{H}_{2} \mathrm{O}\right)_{6}\right]\left(\mathrm{NO}_{3}\right)_{2}$ were added to the above solution and the solution was stirred until a clear red solution was obtained. The compositions of all solutions are given in Table S1.

Synthesis of Mesoporous $\mathrm{MCO}_{2} \mathrm{O}_{4}(\mathrm{M}=\mathrm{Ni}, \mathrm{Mn}$, and $\mathrm{Zn})$ Thin Films and Monoliths. Clear solutions were spread on glass slides via either spin-coating (for thin films) or drop-casting (for monoliths or powders) methods to obtain fresh LLC films or thicker gels, respectively. The thickness of the films can be varied by spin rates or by controlling the volatile solvent (ethanol or water) amounts in the solutions. The spin-coating was done at a spin rate of $2000 \mathrm{rpm}$ for $10 \mathrm{~s}$. This ensures immediate solvent evaporation and gelation. Drop-casting was employed by spreading a few drops of the clear solution over a glass substrate. The drop-cast-coated samples must be kept for 2-3 min under laboratory conditions before inserting them into a preheated oven. This ensures the evaporation of the volatile solvent from the medium to form the gel mesophase. Then, the films were calcined at various temperatures (at $250,300,350,400,450,500$, and $700{ }^{\circ} \mathrm{C}$ ) to produce mesoporous metal cobaltite $\left(\mathrm{m}-\mathrm{MCo}_{2} \mathrm{O}_{4}\right)$ films. The annealing time was $1 \mathrm{~h}$ at each temperature.

Characterization. POM images of the gel phases were recorded using a ZEISS Axio Scope Al polarizing optical microscope. XRD patterns were collected using a Rigaku Miniflex diffractometer, equipped with a $\mathrm{Cu} \mathrm{K} \alpha(\lambda=1.54056 \AA) \mathrm{X}$-ray source, operating at $30 \mathrm{kV} / 15 \mathrm{~mA}$ and a Scintillator $\mathrm{NaI}(\mathrm{T} 1)$ detector with a Be window and a Panalytical X'Pert pro multipurpose X-ray diffractometer equipped with a $\mathrm{Cu} \mathrm{K} \alpha(\lambda=1.5405 \AA) \mathrm{X}$-ray source, operating at 45 $\mathrm{kV} / 40 \mathrm{~mA} . \mathrm{N}_{2}$ adsorption-desorption isotherms were collected using a Micromeritics Tristar 3000 automated gas adsorption analyzer in the range of 0.01 to $0.99 \mathrm{P} / \mathrm{P}_{\mathrm{o}}$. Around $150 \mathrm{mg}$ of sample was dehydrated under a vacuum of $35-40 \mathrm{mT}$ orr at $200{ }^{\circ} \mathrm{C}$ for $2 \mathrm{~h}$ prior to the 

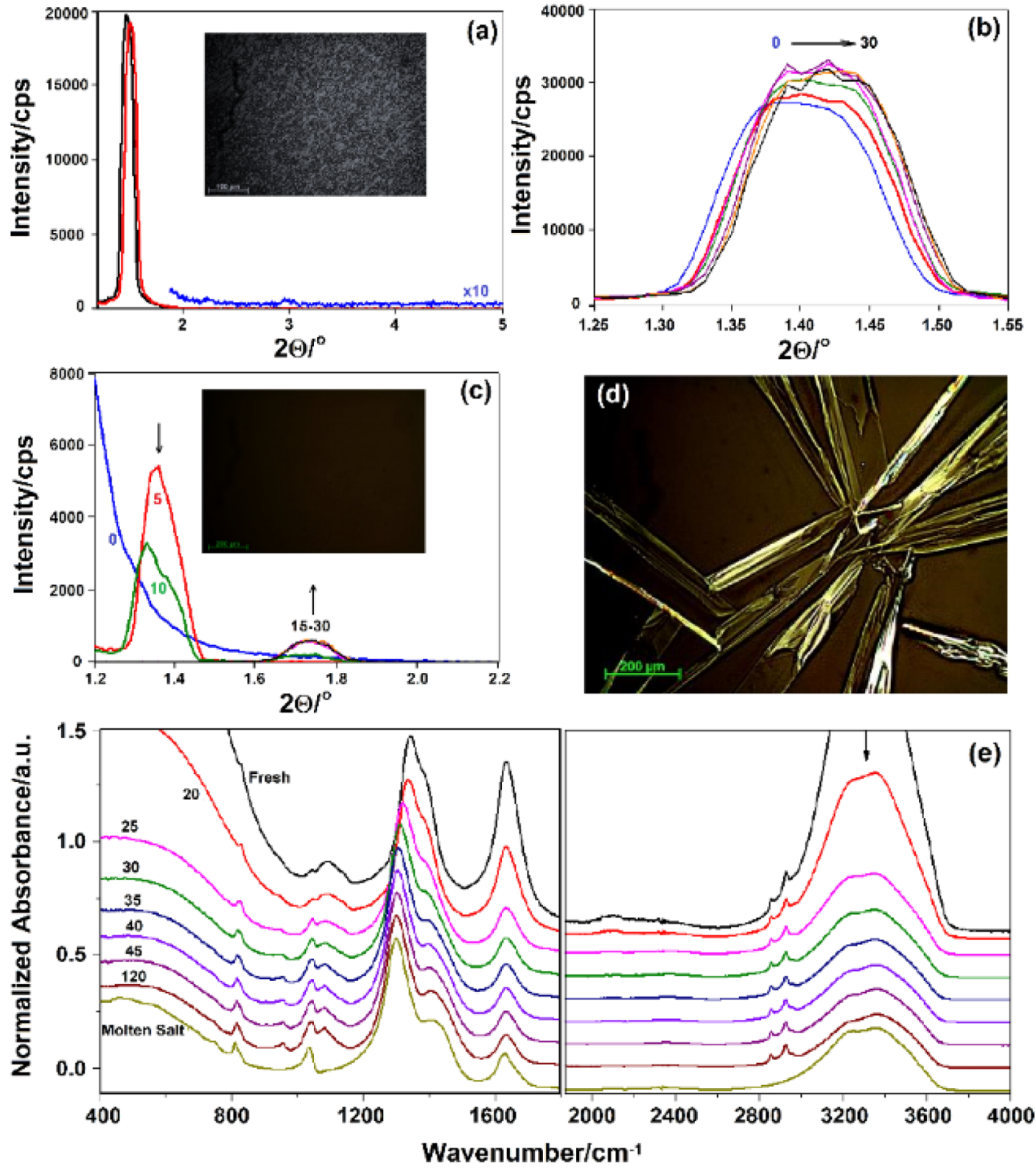

Figure 1. XRD patterns of (a) fresh (black) and aged samples of NiCo-6; the inset shows the POM image of the aged sample, (b) NiCo-8 from spincoated ( $0 \mathrm{~min}$ ) to $30 \mathrm{~min}$ aging (with $5 \mathrm{~min}$ intervals), (c) NiCo-12 (0-fresh, 5, 10, 15-30 min-aged) samples (inset shows the POM image of the fresh sample), (d) POM image of $30 \mathrm{~min}$-aged $\mathrm{NiCo}-12$, and (e) ATR-FTIR spectral changes during solvent evaporation and molten salt (numbers are time in $\min )$.

measurement. Saturated pressure measurements were repeated every $120 \mathrm{~min}$ during a $6-10 \mathrm{~h}$ measurement. The SEM images were recorded using a FEI Quanta $200 \mathrm{~F}$ scanning electron microscope on aluminum sample holders. The XPS spectra were collected using a Thermo Scientific K- $\alpha$ X-ray photoelectron spectrometer operating with a $\mathrm{Al} \mathrm{K} \alpha$ micro-focused monochromatic source $(1486.68 \mathrm{eV}$ and $400 \mu \mathrm{m}$ spot size) along with a flood gun for charge neutralization. The scraped powder samples from fluorine-doped tin oxide (FTO) electrodes were put on a copper tape for XPS analysis and the data were calibrated using the $\mathrm{C} 1 \mathrm{~s}$ peak and/or O 1s peak. XPS spectra of the electrode surface were also recorded by directly inserting the FTOcoated films into the spectrometer and making a contact between the electrode surface and the spectrometer to avoid any surface charging. The electrochemical studies were carried out using $\mathrm{m}-\mathrm{MCo}_{2} \mathrm{O}_{4}$-coated FTO as a working electrode (WE), Pt wire as a counter electrode, and $\mathrm{Ag} / \mathrm{AgCl}(3.5 \mathrm{M} \mathrm{KCl})$ electrode as a reference in a polypropylene cell with $1.0 \mathrm{M} \mathrm{KOH}$ solution. The measurements were performed using a Gamry instrument (potentiostat-PC14G750). The measured poten- tials were corrected and reported as the reversible hydrogen electrode (RHE). Prior to electrochemical measurements, $\mathrm{N}_{2}$ gas was purged into the electrolyte solution for $15 \mathrm{~min}$ to get rid of any dissolved $\mathrm{O}_{2}$. Cyclic voltammetry $(\mathrm{CV})$, chronoamperometry $(\mathrm{CA})$, and chronopotentiometry (CP) measurements were performed subsequently for each electrode. CV curves of the $\mathrm{m}-\mathrm{MCo}_{2} \mathrm{O}_{4}$ electrodes (WEs) were recorded in the potential range of 0.2 to $2.2 \mathrm{~V}$ ( $v \mathrm{RHE}$ ) with a scan rate of $50 \mathrm{mV} / \mathrm{s}$. For each cyclic voltammogram, three cycles were recorded, and the second cycle was presented without IR compensation. In the CA measurements, a pre-determined potential was applied to the WEs to collect the current data. During the experiment, the electrolyte solution was stirred using a magnetic stirrer. At each potential, the potential was applied for 5 to $10 \mathrm{~min}$, depending on how quickly a stable current level was reached; the last current data point is reported and used for further analysis. Tafel slopes were determined with the help of CA experiments. The starting potential for the OER is determined by the first $\mathrm{CV}$ and the earlier potential value is adjusted as a starting point for the CA experiment. The adjusted potential was then applied to the 
WE by CA for $5 \mathrm{~min}$ and the current value at the end of the experiment was reported. This step was repeated with every $20 \mathrm{mV}$ increments, and the current values were obtained for each applied potential. Then, the applied overpotential versus $\log (j)$ was plotted and the linear region was fitted to evaluate the Tafel slopes. The long-term CP and multistep CP experiments were carried at constant current densities of 1 and $10 \mathrm{~mA} /$ $\mathrm{cm}^{2}$ and 10 to $120 \mathrm{~mA} / \mathrm{cm}^{2}$ with $10 \mathrm{~mA} / \mathrm{cm}^{2}$ steps, respectively, to evaluate overpotential values required for the OER process. Potential data were collected for 1 to $48 \mathrm{~h}$ for long-term CPs and 30 min intervals for the multistep CPs while stirring the electrolyte solution using a magnetic stirrer. The last data point was reported as a voltage value of the CP experiment. The potential required for OER was then obtained by subtracting $0.424 \mathrm{~V}[0.424 \mathrm{~V} v s$ normal hydrogen electrode (NHE) from the Nernst equation $E=E^{\circ}-0.0592 \mathrm{pH}$, where $E^{\circ}$ is $1.229 \mathrm{~V}$ and $\mathrm{pH}$ is 13.6] from the collected data to evaluate the overpotential values. Electrochemically produced $\mathrm{O}_{2}$ gas was collected using a threeelectrode cell, which is isolated using a parafilm, and the headspace of the flask (cell) was sealed with septa to determine the Faradaic efficiency of OER. The reaction solution $(1 \mathrm{M} \mathrm{KOH})$ was purged thoroughly using $\mathrm{N}_{2}$ gas to remove any air in the electrolyte mixture for $30 \mathrm{~min}$ prior to each sampling for gas chromatography (GC) measurements. The CA experiment was conducted twice at $1 \mathrm{~V}$ ( vs NHE) for 10 and $30 \mathrm{~min}$ for each electrode. The sample was taken from the headspace of the cell using a $100 \mu \mathrm{L}$ syringe and injected into the GC system (Agilent 7820 A GC, equipped with a Molsieve column and a TCD detector) to detect the $\mathrm{O}_{2}$ and $\mathrm{N}_{2}$ gases each time. Ar was used as the carrier gas. Isolation and leakage tests were done by the $\mathrm{N}_{2}$ amount (for an ideal experiment, the $\mathrm{N}_{2}$ amount should remain constant throughout the experiment). The area under the peak of $\mathrm{O}_{2}$ is used for the calculation of $\mathrm{O}_{2}$ amount. Theoretical and experimental oxygen amounts were calculated using CA and GC data, respectively.

\section{RESULTS AND DISCUSSION}

By adapting the MASA method, we have developed a new method to synthesize mesoporous $\mathrm{MCo}_{2} \mathrm{O}_{4}$ thin films. Three different metal salts $\left(\left[\mathrm{Mn}\left(\mathrm{H}_{2} \mathrm{O}\right)_{4}\right]\left(\mathrm{NO}_{3}\right)_{2},\left[\mathrm{Ni}\left(\mathrm{H}_{2} \mathrm{O}\right)_{6}\right]\right.$ $\left(\mathrm{NO}_{3}\right)_{2}$, and $\left.\left[\mathrm{Zn}\left(\mathrm{H}_{2} \mathrm{O}\right)_{6}\right]\left(\mathrm{NO}_{3}\right)_{2}\right)$ have been chosen to demonstrate the versatility of the method and two different surfactant types (namely, $\mathrm{C}_{12} \mathrm{H}_{25}\left(\mathrm{OCH}_{2} \mathrm{CH}_{2}\right)_{10} \mathrm{OH}, \mathrm{C}_{12} \mathrm{E}_{10}$, and $\mathrm{H}-\left(\mathrm{OCH}_{2} \mathrm{CH}_{2}\right)_{20}-\left(\mathrm{OCH}_{2} \mathrm{CH}\left(\mathrm{CH}_{3}\right)\right)_{70}-$ $\left.\left(\mathrm{OCH}_{2} \mathrm{CH}_{2}\right)_{20}-\mathrm{OH}, \mathrm{P} 123\right)$ together with a charged surfactant $\left(\mathrm{C}_{16} \mathrm{H}_{33} \mathrm{~N}\left(\mathrm{CH}_{3}\right)_{3} \mathrm{Br}, \mathrm{CTAB}\right)$ were employed. $\mathrm{C}_{12} \mathrm{E}_{10}$ has been used in the synthesis of mesoporous $\mathrm{MCo}_{2} \mathrm{O}_{4}[\mathrm{M}=\mathrm{Mn}(\mathrm{II})$ and $\mathrm{Ni}(\mathrm{II})]$ and $\mathrm{P} 123$ for $\mathrm{NiCo}_{2} \mathrm{O}_{4}$ and $\mathrm{ZnCo}_{2} \mathrm{O}_{4}$. The key steps in the synthesis or MASA process are obtaining a clear homogeneous solution of the ingredients and determining the stability of the LLC phase that forms upon coating the clear solution. Since these two surfactants have different sizes and masses, the salt-surfactant ratios are also quite different. First, we have adapted our previous work on the synthesis of mesoporous metal oxides to optimize the salt/surfactant ratios for stable mesophases. In the salts $-\mathrm{C}_{12} \mathrm{E}_{10}$ systems, the total salt $(\mathrm{M}(\mathrm{II})+2 \mathrm{Co}(\mathrm{II})) /$ surfactant mole ratios were varied from 2 to 25 and from 10 to 90 in the P123 system by keeping the metal ion [ $\mathrm{Mn}(\mathrm{II}), \mathrm{Ni}(\mathrm{II})$, or $\mathrm{Zn}(\mathrm{II})]$ to $\mathrm{Co}(\mathrm{II})$ mole ratio as 1 to 2 . Therefore, each of the salt systems was investigated in solution, gel, and mesoporous forms. The solution phases require extended stirring (several hours to a day) to ensure the complete dissolution of salt and surfactant species in order to obtain homogeneous clear solutions. If not done, the remaining undissolved salt nano-crystallites in the solution grow very quickly upon spin coating and separate as crystals embedded in the gel. However, if one dissolves salt species completely, the mesophase keeps the salt species in their molten phase in the confined hydrophilic space of mesophase. ${ }^{41}$ This effect is known as the nano-space effect, which is also the origin of stable salt- surfactant mesophases. ${ }^{41}$ In the nano-space, the melting point of salt is quite low [as low as $-52{ }^{\circ} \mathrm{C}$ in $\left.\mathrm{Zn}(\mathrm{II})\right]^{41}$ and there is no space for salt species to reach the seed size of the salt to further grow and crystallize. In other words, the seeding step for the salt crystallization does not occur in the mesophase due to space restriction. However, the salt crystallization may take place from the defect sides of the mesophase. The defects can be observed in the POM images (dark domains) of anisotropic mesophases, see Figure 1. At extremely high salt concentrations, salt species begin to leach from the ordered mesodomains into the disordered salt-free defect regions and crystallize. Also note that the solubility of salt in the disordered defect sides or, in general, in the surfactants are extremely low (almost none). It is impossible to dissolve and mix salt species if the salt to surfactant mole ratio is below 1 . The mesophase formation in the saltsurfactant system is a result of self-assembly of molten salt as solvent and surfactant molecules, such as water-surfactant LLC phases. $^{43,44}$ This is also the foundation of the MASA process, in which we use two surfactants and an additional volatile solvent (water or ethanol) in the salt-surfactant mesophases. The second surfactant is a charged surfactant, and it is used to increase the salt concentration in the hydrophilic domains of the mesophase. ${ }^{42}$ A second volatile solvent is needed to process the LLCM as thin films. Coating clear solutions with all ingredients results in the formation of an LLCM in a short time.

Lyotropic Liquid Crystalline Mesophases of $(\mathrm{M}(\mathrm{II})+$ 2Co(II))-Surfactant Systems. Both $\mathrm{Ni}$ (II) and $\mathrm{Mn}$ (II) (with $\mathrm{C}_{12} \mathrm{E}_{10}$ ) systems form clear solutions up to a [ $8.3 \mathrm{Ni}$ (II) and 16.7 $\mathrm{Co}(\mathrm{II})]$ salt/surfactant mole ratio of 25 . This corresponds to around $89 \mathrm{w} / \mathrm{w} \%$ salt in the LLC medium. This is an extremely high salt concentration and shows the flexibility and stability of LLCMs. However, at such high salt concentrations, the mesophase is not stable and quickly leaches out salt crystals (minutes). However, the LLCM becomes stable by decreasing the amount of salt, such that it is forever stable below a salt/ surfactant mole ratio of 6 . This corresponds to around $66 \mathrm{w} / \mathrm{w} \%$ salt in the mesophase. Moreover, the mesophases are stable long enough for further processes (such as calcination) up to a mole ratio of 12 . At salt/surfactant mole ratios higher than 12 , the mesophases must be calcined immediately after coating to produce their mesoporous films.

The salt/surfactant mole ratio is important in further steps to hold the mesostructure during the calcination process. The LLCM of the samples was denoted MCo-\# ( $\mathrm{M}$ is Ni or Mn and \# is the total salt to $\mathrm{C}_{12} \mathrm{E}_{10}$ mole ratio). Figure 1 shows a series of small-angle XRD patterns and POM images of NiCo-6, NiCo-8, and NiCo-12 samples in their LLC phase. The mesophase is $2 \mathrm{D}$ hexagonal up to salt concentrations of 6 , as evidenced from the fan texture in the POM image and XRD lines at small angles, see the inset in Figure 1a. POM images become dark above the mole ratio of 6, see the inset in Figure 1c, but these compositions still diffract at small angles and display characteristic XRD line(s) at small angles (see Figure 1c), together showing that the mesophase is cubic. Also note that the fan texture reappears in the samples above salt ratios of 6 over time (upon aging the gel phase), indicating salt crystallization. Simply, the crystallization of excess molten salt reduces the salt/surfactant mole ratio below 6 , at which point the mesophase is $2 \mathrm{D}$ hexagonal, see Figure $1 \mathrm{~b}$. Also note that at high salt concentrations, the salt crystallization is more obvious. Figure $1 \mathrm{~d}$ shows a POM image of an aged sample of NiCo-12. It leaches out excess salt, indicating a metastable mesophase. The NiCo-12 sample shows diffraction at around $1.35^{\circ}$ ( $d$ spacing is $65.4 \AA$ ) for $5 \mathrm{~min}$, but the 

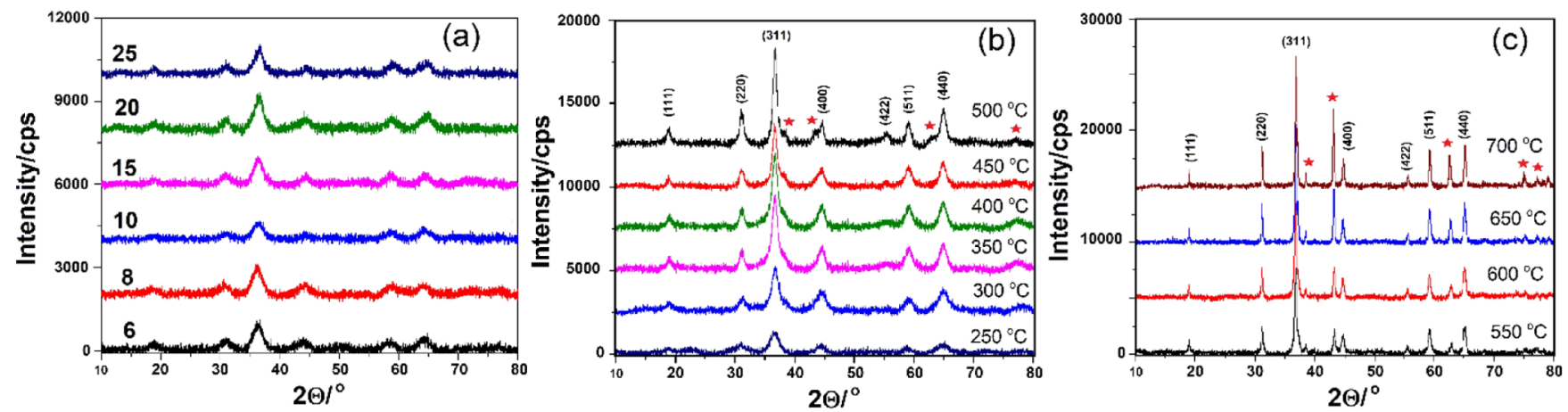

Figure 2. XRD patterns of (a) $\mathrm{m}-\mathrm{NiCo}_{2} \mathrm{O}_{4}-n-250$ ( $n$ are given in the patterns) and ( $\mathrm{b}$ and c) $\mathrm{m}-\mathrm{NiCo}_{2} \mathrm{O}_{4}-10-\mathrm{XXX}$ (XXX are given in the patterns, indexed using PDF card no: 00-020-0781).

diffraction line declines in time and a new line appears at around $1.74^{\circ}, 2 \theta$ ( $d$ spacing is $50.7 \AA$ ), in $10 \mathrm{~min}$; the small-angle line at $1.35^{\circ}, 2 \theta$, completely disappears in $15 \mathrm{~min}$, see Figure $1 \mathrm{c}$. The changes in the XRD pattern are due to salt crystallization which causes a shrinkage in the unit cell by $29 \%$ if we assume that both lines (at 1.35 and $1.74^{\circ}, 2 \theta$ ) originate from the same diffraction plane of the same phase. Also note that the changes in the XRD patterns are negligible up to a salt mole ratio of 6 but more drastic at higher salt ratios due to salt leaching and phase changes. Similar behaviors were also observed in the MnCo-\# phases, see Figure S1.

In addition, we monitored the evaporation of excess water and the gelation process using ATR-FTIR spectroscopy (see Figure 1e). Clearly, there are several spectral changes in different regions of the spectra over time during the gelation process, such as the water-stretching and -bending regions (a broad feature at around $3200 \mathrm{~cm}^{-1}$ and a sharp peak at around $1640 \mathrm{~cm}^{-1}$ ) lose intensity due to evaporation of excess water, a new peak emerges at around $1040 \mathrm{~cm}^{-1}$ due to the nitrate ion (this mode is IR inactive in the free nitrate ion, symmetric stretching mode), splitting of the most intense peak due to asymmetric stretching mode of the nitrate ion (around $1350 \mathrm{~cm}^{-1}$ ), and changes in the surfactant-related peaks (around 1100 and $2800 \mathrm{~cm}^{-1}$ regions). The spectrum at the bottom was recorded from the molten mixture of $1: 2 \mathrm{Mn}(\mathrm{II}) / \mathrm{Co}(\mathrm{II})$ nitrate hydrate salts. The spectra after complete water evaporation (gelation, in $40-45 \mathrm{~min}$ ) are remarkably like those of the molten salt in the nitrate and water regions. The similarity in the nitrate and water spectral regions is strong evidence that the salt species act as a non-volatile solvent in the assembly of surfactant molecules into LLCMs. The use of $\mathrm{P} 123$ in place of $\mathrm{C}_{12} \mathrm{E}_{10}$ does not alter the behavior of the mesophases, but the salt/P123 mole ratio could be increased up to a mole ratio of 90 (corresponding to about $79 \mathrm{w} / \mathrm{w} \%$ salt and $21 \mathrm{w} / \mathrm{w} \%$ surfactants). In the P123 system, three compositions were chosen and investigated in the gel phase and later used to produce mesoporous $\mathrm{ZnCo}_{2} \mathrm{O}_{4}$ thin films; these are 30 (low), 60 (intermediate), and 90 (high) salts $(1: 2 \mathrm{Zn}$ (II)/Co(II) mole ratio) per $\mathrm{P} 123$ molecule and denoted $\mathrm{ZnCo}-30, \mathrm{ZnCo}-60$, and $\mathrm{ZnCo}-90$, respectively. We have also investigated the $\mathrm{Ni}(\mathrm{II}) /$ $\mathrm{Co}(\mathrm{II})-\mathrm{P} 123$ system because of the advantages of P123 (see later). Figure $S 2$ shows the XRD patterns of fresh and aged LLC gel phases of $\mathrm{ZnCo}-\#$ (\# is 30, 60, and 90). The three compositions were used to determine the best salt-surfactant composition in order to produce high-quality porous $\mathrm{ZnCo}_{2} \mathrm{O}_{4}$ thin films. Since the mesophases of $\mathrm{ZnCo}-30$ and $\mathrm{ZnCo}-60$ are stable for some duration (sufficiently long to calcine the sample before any salt crystallization), these two compositions were used in the synthesis of mesoporous $\mathrm{ZnCo}_{2} \mathrm{O}_{4}$ but were preferentially characterized using the samples prepared from $\mathrm{ZnCo}-60$ in order to minimize the surfactant use in the process.

Also note that the presence of a charged surfactant stabilizes the mesophases at high salt concentrations. ${ }^{42}$ Therefore, 1 and 5 CTAB units per $\mathrm{C}_{12} \mathrm{E}_{10}$ and $\mathrm{P} 123$, respectively, were added to the medium to stabilize the mesophases at high salt concentrations, as established previously. ${ }^{37,38}$ However, the presence of $\mathrm{CTAB}$ in the medium also causes crystallization of the (CTA $)_{2}\left[\mathrm{MBr}_{4}\right]$ complex surfactant. ${ }^{36}$ Also notice that the crystals that leached out from the $\mathrm{ZnCo-30}$ sample, after 1 day aging in the gel phase, are of the complex surfactant. However, the latter composition only leaches out salt crystals, see Figure S2. Simply, the complex surfactant crystallization could be hindered by increasing the salt concentration in the medium. Similarly, salt crystallization may be hindered to some extent by increasing the $\mathrm{CTAB}$ concentration in the medium. ${ }^{42}$ Moreover, salt crystallization is a slow process and may be avoided if one can calcine the fresh samples, as in spin-coating, or one can use $\mathrm{CTANO}_{3}$ as a charged surfactant; however, its preparation requires tedious steps. ${ }^{36}$ Therefore, we have used $\mathrm{CTAB}$ as a charged surfactant and the calcination was carried out immediately after coating.

Mesoporous $\mathrm{MCO}_{2} \mathrm{O}_{4}(\mathrm{M}=\mathrm{Mn}(\mathrm{II}), \mathrm{Ni}(\mathrm{II})$, and $\mathrm{Zn}(\mathrm{II}))$ Thin Films and Monoliths. The $\mathrm{Ni}(\mathrm{II})-\mathrm{Co}(\mathrm{II})-\mathrm{C}_{12} \mathrm{E}_{10}$ system has been investigated in detail using seven solutions (with salt to surfactant mole ratios of 6, 8, 10, 12, 15, 20, and 25). Spin-coating of the solutions produces thin gels of LLCM films. Drop-casting was also employed to obtain samples in large quantities as monoliths. Both spin-coating and drop-casting, followed by calcination yield samples that display similar $\mathrm{N}_{2}$ adsorption-desorption isotherms and XRD patterns. Therefore, the spin-coating method has been used to produce thin-film electrodes (see later), but the drop-casting method was used where a large amount of sample was required, such as in the measurements of $\mathrm{N}_{2}$ adsorption-desorption isotherms and XRD patterns. The calcined mesoporous samples are denoted $\mathrm{m}-\mathrm{NiCo}_{2} \mathrm{O}_{4}-n-\mathrm{XXX}$ (where $n$ is the salt-surfactant mole ratio and XXX is the calcination temperature).

Figure 2a shows a set of XRD patterns of monoliths, calcined at $250{ }^{\circ} \mathrm{C}$. Clearly, even at $250{ }^{\circ} \mathrm{C}$, the resulting samples are crystalline, and the diffraction lines can be indexed to spinel $\mathrm{NiCo}_{2} \mathrm{O}_{4}$. The diffraction lines become sharper with increasing calcination temperature, see Figure $2 \mathrm{~b}$. The crystallite size, calculated using Scherrer's equation, increases from 4.5 to 12.4 $\mathrm{nm}$ by increasing the calcination/annealing temperature from 250 to $500{ }^{\circ} \mathrm{C}$, respectively, see other particle sizes at other 
temperatures in Table 1 . There is no secondary phase in the samples of $\mathrm{m}-\mathrm{NiCo}_{2} \mathrm{O}_{4}-n-250$ ( $n$ is 10 and above), but the

Table 1. Particle Size $(D, \mathrm{~nm})$, as Calculated from Scherrer's Equation $[D=0.9 \lambda /(\beta \cos \theta)$, Where $\lambda$ Is $0.154056 \mathrm{~nm} ; \beta$ and $\theta$ Are fwhm after Instrumental Broadening and Angle of the (311) Line, Respectively], of $\mathrm{m}-\mathrm{MCo}_{2} \mathrm{O}_{4}$ Films at Different Calcination Temperatures

\begin{tabular}{ccccrrr} 
& \multicolumn{7}{c}{$\mathrm{D}(\mathrm{nm})$} \\
\cline { 2 - 7 } sample/temperature $\left({ }^{\circ} \mathrm{C}\right)$ & 250 & 300 & 350 & 400 & 450 & 500 \\
$\mathrm{~m}-\mathrm{NiCo}_{2} \mathrm{O}_{4}$ & 4.5 & 7.6 & 8.9 & 9.6 & 11.3 & 12.4 \\
$\mathrm{~m}-\mathrm{MnCo}_{2} \mathrm{O}_{4}$ & 4.4 & 4.6 & 4.7 & 4.8 & 5.2 & 5.7 \\
$\mathrm{~m}-\mathrm{ZnCo}_{2} \mathrm{O}_{4}$ & 6.5 & 6.6 & 7.6 & 10.3 & 15.2 & 15.8 \\
\hline
\end{tabular}

samples prepared using salt/surfactant mole ratios of 6 and 8 also display weak secondary lines due to the metal hydroxide species. However, these two samples are also crystalline spinel $\mathrm{NiCo}_{2} \mathrm{O}_{4}$ at $300{ }^{\circ} \mathrm{C}$ and above. On further annealing or direct calcination at around $500{ }^{\circ} \mathrm{C}$, two new very weak lines appear at 43.5 and $63.2^{\circ}, 2 \theta$, due to (200) and (220), respectively, of rock salt $\mathrm{NiO}$. With further annealing, these lines and some new lines of $\mathrm{NiO}$ merge and intensify. This is commonly observed in the spinel $\mathrm{NiCo}_{2} \mathrm{O}_{4}$ phase in the literature. ${ }^{45}$ The origin of the $\mathrm{NiO}$ phase may be due to either phase separation of $\mathrm{m}-\mathrm{NiCo}_{2} \mathrm{O}_{4}$ into $\mathrm{NiO}$ and $\mathrm{Co}_{3} \mathrm{O}_{4}$ phases or crystallization of amorphous $\mathrm{NiO}$ domains in the pore walls. To test this, $\mathrm{m}-\mathrm{NiCo}_{2} \mathrm{O}_{4}$ was further annealed step-by-step from 550 to $700{ }^{\circ} \mathrm{C}$, see Figure $2 \mathrm{c}$. Note that mesoporous $\mathrm{NiO}$ synthesized by MASA crystallizes at around $300{ }^{\circ} \mathrm{C}$ and becomes highly crystalline over $400{ }^{\circ} \mathrm{C} .{ }^{38}$ However, the crystallization of $\mathrm{NiO}$ domains may be hindered due to strong $\mathrm{NiO}-\mathrm{NiCo}_{2} \mathrm{O}_{4}$ interactions at the interface on top of the films or within the pore walls. Also notice that the intensity of $\mathrm{NiO}$ lines increases more than that of the $\mathrm{NiCo}_{2} \mathrm{O}_{4}$ lines with annealing at higher temperatures, indicating a phase separation, but this still may not be sufficient evidence to overrule the growth of $\mathrm{NiO}$, coming out from the surface and between the $\mathrm{NiCo}_{2} \mathrm{O}_{4}$ domains of the pore walls. Also note that there is no change in the $\mathrm{NiCo}_{2} \mathrm{O}_{4}$ lines other than sharpening with further crystallization.

The same samples were also used to collect $\mathrm{N}_{2}$ adsorptiondesorption isotherms. Figures $3 \mathrm{a}, \mathrm{b}$ and S3 display a set of isotherms and pore-size distribution plots. Clearly, all samples are mesoporous at all compositions. The isotherms are typical, type IV, and characteristic for the mesoporous materials. ${ }^{46}$ The pore-size distributions become less uniform with the increase of salt amount in the mesophase (see Figure S3). Table 2 shows the Brunauer-Emmett-Teller (BET) surface area, Barrett-Joyner-Halenda $(\mathrm{BJH})$ pore volume, and $\mathrm{BJH}$ pore size of $\mathrm{m}$ $\mathrm{NiCo}_{2} \mathrm{O}_{4}-n-250$. Among these samples, the highest surface area was recorded to be $223 \mathrm{~m}^{2} / \mathrm{g}$ from the $\mathrm{m}-\mathrm{NiCo}_{2} \mathrm{O}_{4}-10-250$ sample. All samples display similar pore volumes, but the pore size gradually increases from 3.5 to $6.0 \mathrm{~nm}$ with the increase of $n$ from 6 to 25, respectively; comparison data are provided in Table 2. Since the highest surface area was obtained from a mole ratio of $10, \mathrm{~m}-\mathrm{NiCo}_{2} \mathrm{O}_{4}-10$ was further investigated at higher temperatures. Figure $3 \mathrm{a}, \mathrm{b}$ shows the changes in the $\mathrm{N}_{2}$ adsorption-desorption isotherms and pore-size distributions of $\mathrm{m}-\mathrm{NiCo}_{2} \mathrm{O}_{4}-10-\mathrm{XXX}$ (where XXX was varied between 300 and $500{ }^{\circ} \mathrm{C}$ ). The surface area of the sample decreases with increasing calcination temperature (from $172 \mathrm{~m}^{2} / \mathrm{g}$ at $300{ }^{\circ} \mathrm{C}$ to $31 \mathrm{~m}^{2} / \mathrm{g}$ at $500{ }^{\circ} \mathrm{C}$ ). Similarly, the pores expand from 6.9 to 25.6 $\mathrm{nm}$. However, the pore volume remains almost unaltered, indicating that the pores are expanding at the expense of smaller pores. Details of the $\mathrm{N}_{2}$ adsorption-desorption data are tabulated in Table 2.

SEM and TEM images of the samples were also obtained to show the film morphology and pore system. Figure $4 a-c$ show SEM images of samples obtained at mole ratios of 6,15 , and 25 . Clearly, the samples with mole ratios of 6 and 15 have uniform film morphologies, but the $\mathrm{m}-\mathrm{NiCo}_{2} \mathrm{O}_{4}-25$ sample is more fragile and less rigid. The mesopores of the samples, calcined at higher temperatures, are resolved and clearly visible in the SEM images of the samples; for samples calcined at 450 and $500{ }^{\circ} \mathrm{C}$, see Figure 4d,e. Figure 5 shows a set of high-angle annular darkfield STEM and TEM images of $\mathrm{m}-\mathrm{MCo}_{2} \mathrm{O}_{4}$ samples. The sponge-like pores are clearly visible but disordered throughout the films, see Figure 5a,b. The pore walls are constructed of crystalline nanoparticles of $\mathrm{MCo}_{2} \mathrm{O}_{4}$, see Figure 5c. Both SEM and TEM images accord well with the $\mathrm{N}_{2}$ adsorptiondesorption data and XRD patterns.

$\mathrm{MnCo}_{2} \mathrm{O}_{4}$ samples were also prepared using the same method and compositions. Freshly prepared and aged samples of the $\mathrm{Mn}(\mathrm{II})-\mathrm{Co}(\mathrm{II})-\mathrm{C}_{12} \mathrm{E}_{10}$ system were extensively investigated using seven different compositions (total salt/ $\mathrm{C}_{12} \mathrm{E}_{10}$ mole ratios of $6,8,10,12,15,20$, and 25) from solution to gelation and then to calcination. MnCo-\# samples behave like the $\mathrm{NiCo}$-\# samples. Both $\mathrm{Mn}$ (II) and Co(II) salts synergistically affect each other's miscibility and phase stability. Even at a salt/ surfactant mole ratio of 12 , the mesophase is stable for long periods, see Figure S1. All compositions were calcined and investigated (details of all compositions are given in the
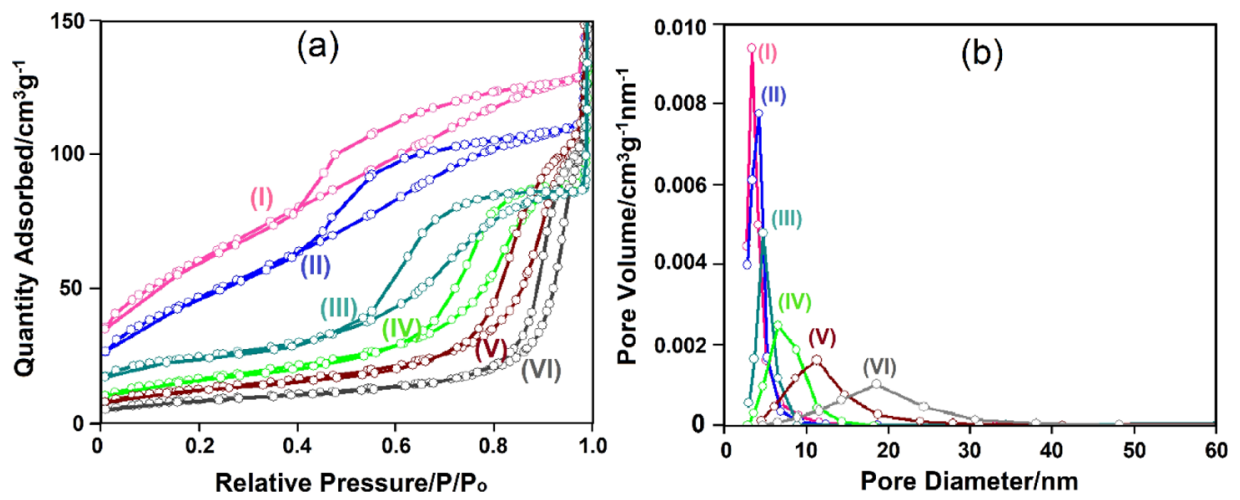

Figure 3. (77 K) $\mathrm{N}_{2}$ adsorption-desorption isotherms (a) and pore-size distribution plots (b) of $\mathrm{m}-\mathrm{NiCo}_{2} \mathrm{O}_{4}-10-\mathrm{XXX}$ samples [XXX is (I) 250, (II) 300, (III) 350, (IV) 400, (V) 450, and (VI) $\left.500{ }^{\circ} \mathrm{C}\right]$. 
Table 2. $\mathrm{N}_{2}(77 \mathrm{~K})$ Adsorption-Desorption Data of $\mathrm{m}-\mathrm{NiCo}_{2} \mathrm{O}_{4}-n-\mathrm{XXX}, \mathrm{m}-\mathrm{MnCo}_{2} \mathrm{O}_{4}-n-\mathrm{XXX}$, and $\mathrm{m}-\mathrm{ZnCo} \mathrm{O}_{4}-\mathrm{XXX}(20: 40 \mathrm{Zn} /$ Co Mole Ratio). SA Is the BET Surface Area, PV Is the BJH Pore Volume, and PS Is the BJH Pore Size

\begin{tabular}{|c|c|c|c|c|c|c|c|}
\hline sample & $S_{\mathrm{BET}}^{a}\left(\mathrm{~m}^{2} / \mathrm{g}\right)$ & $V_{\mathrm{P}}^{b}\left(\mathrm{~cm}^{3} / \mathrm{g}\right)$ & $D_{\mathrm{P}}{ }^{c}(\mathrm{~nm})$ & Sample & $S_{\mathrm{BET}}{ }^{a}\left(\mathrm{~m}^{2} / \mathrm{g}\right)$ & $V_{\mathrm{P}}^{b}\left(\mathrm{~cm}^{3} / \mathrm{g}\right)$ & $D_{\mathrm{P}}{ }^{c}(\mathrm{~nm})$ \\
\hline $\mathrm{m}-\mathrm{NiCo}_{2} \mathrm{O}_{4}-6-250$ & 175 & 0.145 & 3.5 & $\mathrm{~m}-\mathrm{MnCo}_{2} \mathrm{O}_{4}-12-250$ & 204 & 0.215 & 3.0 \\
\hline $\mathrm{m}-\mathrm{NiCo}_{2} \mathrm{O}_{4}-8-250$ & 148 & 0.161 & 3.9 & $\mathrm{~m}-\mathrm{MnCo}_{2} \mathrm{O}_{4}-12-300$ & 174 & 0.236 & 3.2 \\
\hline $\mathrm{m}-\mathrm{NiCo}_{2} \mathrm{O}_{4}-10-250$ & 223 & 0.191 & 3.9 & $\mathrm{~m}-\mathrm{MnCo}_{2} \mathrm{O}_{4}-12-350$ & 164 & 0.194 & 3.2 \\
\hline $\mathrm{m}-\mathrm{NiCo}_{2} \mathrm{O}_{4}-12-250$ & 172 & 0.198 & 4.5 & $\mathrm{~m}-\mathrm{MnCo}_{2} \mathrm{O}_{4}-12-400$ & 142 & 0.243 & 3.3 \\
\hline $\mathrm{m}-\mathrm{NiCo}_{2} \mathrm{O}_{4}-15-250$ & 115 & 0.139 & 4.5 & $\mathrm{~m}-\mathrm{MnCo}_{2} \mathrm{O}_{4}-12-450$ & 125 & 0.290 & 3.5 \\
\hline $\mathrm{m}-\mathrm{NiCo}_{2} \mathrm{O}_{4}-20-250$ & 142 & 0.205 & 5.6 & $\mathrm{~m}-\mathrm{MnCo}_{2} \mathrm{O}_{4}-12-500$ & 83 & 0.193 & 3.9 \\
\hline $\mathrm{m}-\mathrm{NiCo}_{2} \mathrm{O}_{4}-25-250$ & 128 & 0.187 & 6.0 & $\mathrm{~m}-\mathrm{ZnCo}_{2} \mathrm{O}_{4}-60-250$ & 124 & 0.231 & 7.1 \\
\hline $\mathrm{m}-\mathrm{NiCo}_{2} \mathrm{O}_{4}-10-300$ & 172 & 0.322 & 6.9 & $\mathrm{~m}-\mathrm{ZnCo}_{2} \mathrm{O}_{4}-60-300$ & 92 & 0.220 & 6.8 \\
\hline $\mathrm{m}-\mathrm{NiCo}_{2} \mathrm{O}_{4}-10-350$ & 86 & 0.211 & 7.4 & $\mathrm{~m}-\mathrm{ZnCo}_{2} \mathrm{O}_{4}-60-350$ & 102 & 0.325 & 9.6 \\
\hline $\mathrm{m}-\mathrm{NiCo}_{2} \mathrm{O}_{4}-10-400$ & 60 & 0.197 & 10 & $\mathrm{~m}-\mathrm{ZnC \textrm {n } _ { 2 }} \mathrm{O}_{4}-60-400$ & 70 & 0.279 & 11.3 \\
\hline $\mathrm{m}-\mathrm{NiCo}_{2} \mathrm{O}_{4}-10-450$ & 46 & 0.327 & 21.5 & $\mathrm{~m}-\mathrm{ZnC \textrm {n } _ { 2 }} \mathrm{O}_{4}-60-450$ & 53 & 0.301 & 16.6 \\
\hline $\mathrm{m}-\mathrm{NiCo}_{2} \mathrm{O}_{4}-10-500$ & 31 & 0.236 & 25.6 & $\mathrm{~m}-\mathrm{ZnCo} \mathrm{O}_{4}-60-500$ & 44 & 0.298 & 19.2 \\
\hline
\end{tabular}

${ }^{a} \mathrm{BET}$ surface area determined from the linear part of BET equation $\left(P / P_{\mathrm{o}}=0.05-025\right) .{ }^{b}$ Total pore volume determined as $P / P_{\mathrm{o}}=0.99 .{ }^{c}$ Pore diameter from the desorption branch.
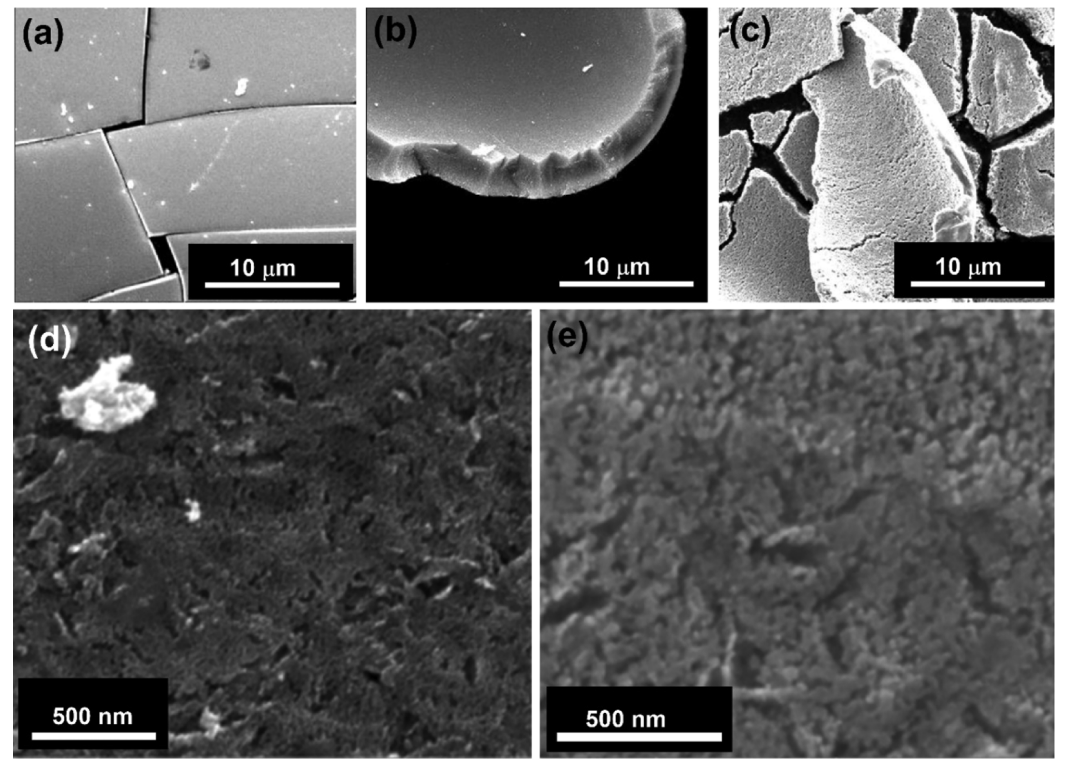

Figure 4. SEM images of $\mathrm{m}-\mathrm{NiCo}_{2} \mathrm{O}_{4}$ \#-300, where \# is (a) 6 (inset is a 4 times magnified small part of the image), (b) 15, and (c) 25. SEM images of the sample calcined at (d) 450 and (e) $500{ }^{\circ} \mathrm{C}$.
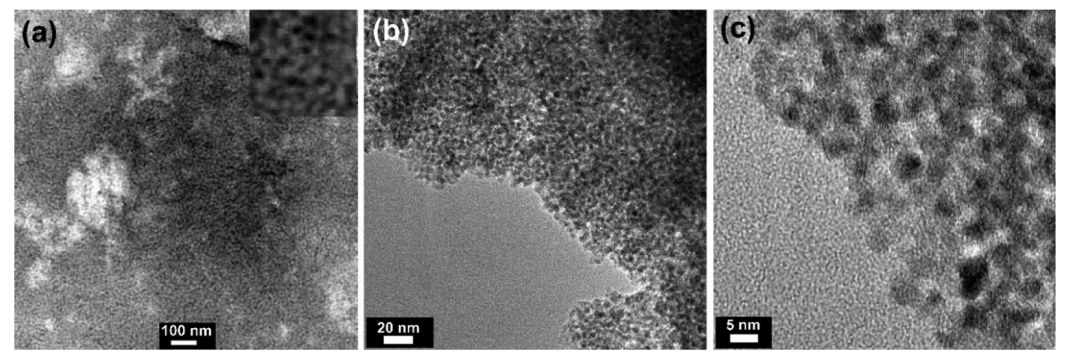

Figure 5. (a) HAADF image of $\mathrm{m}-\mathrm{NiCo}_{2} \mathrm{O}_{4}-10-350$ (inset is 4 times magnified image) and (b,c) TEM images of $\mathrm{m}-\mathrm{MnCo}_{2} \mathrm{O}_{4}-10-350$ at different magnifications.

Supporting Information section, Table S1), but most of the efforts have been devoted to composition with a $(\mathrm{Mn}(\mathrm{II})+2 \mathrm{Co}$ (II) $) / \mathrm{C}_{12} \mathrm{E}_{10}$ mole ratio of 10 . Samples prepared at those compositions were further characterized (by recording their temperature-dependent XRD patterns and $\mathrm{N}_{2}$ adsorptiondesorption isotherms) and investigated electrochemically (see later). Clearly, the spinel $\mathrm{m}-\mathrm{MnCo}_{2} \mathrm{O}_{4}$ forms at as low as $250{ }^{\circ} \mathrm{C}$, see Figure S4a. However, the growth of the pore walls is postponed until $550{ }^{\circ} \mathrm{C}$. Table 1 lists the size of the $\mathrm{MnCo}_{2} \mathrm{O}_{4}$ nano-crystallites, calculated using Scherrer's equation and the (311) line in the XRD patterns. The XRD lines are quite broad up to $500{ }^{\circ} \mathrm{C}$ (particle size increases only $30 \%$, from 4.4 to 5.7 $\mathrm{nm}$ by annealing from 250 to $500{ }^{\circ} \mathrm{C}$ ), but above $550{ }^{\circ} \mathrm{C}$, the nanocrystalline $\mathrm{MnCo}_{2} \mathrm{O}_{4}$ pore walls grow (it is $8.2 \mathrm{~nm}$ at 550 ${ }^{\circ} \mathrm{C}$, another $44 \%$ growth and then it grows to 19,26 , and $49 \mathrm{~nm}$ at 600,650 , and $700{ }^{\circ} \mathrm{C}$, respectively); however, no phase 

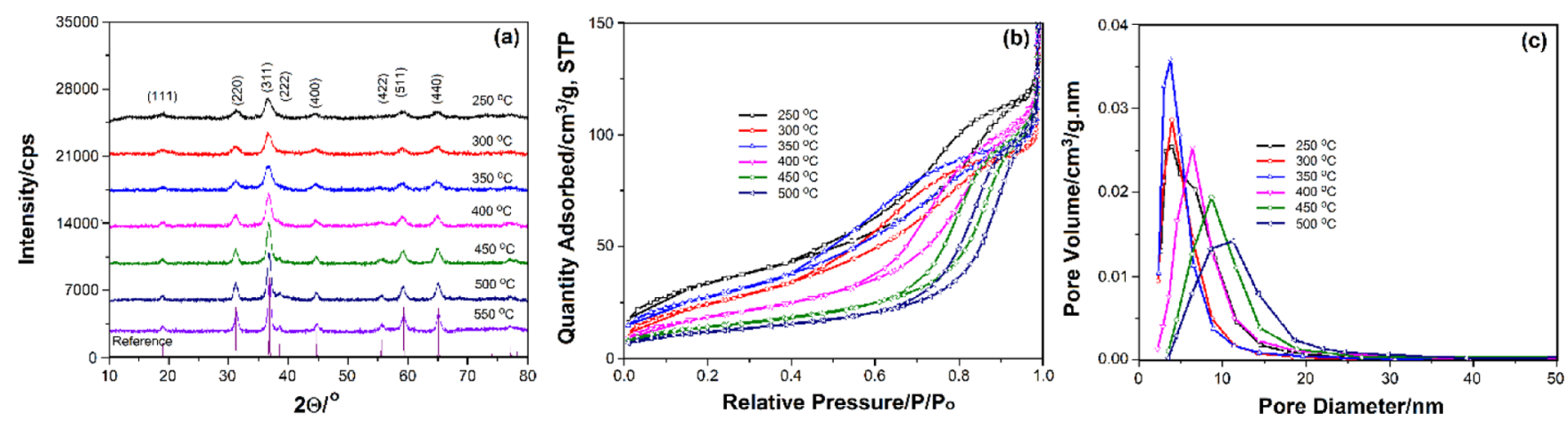

Figure 6. $\mathrm{m}-\mathrm{ZnCo}_{2} \mathrm{O}_{4}-60-\mathrm{XXX}$ : (a) PXRD patterns (XXX is 250, 300, 350, 400, 450, 500, and $550{ }^{\circ} \mathrm{C}$, as indicated by the patterns, bottom pattern is the reference, PDF card no: 00-023-1390), $\mathrm{N}_{2}$ adsorption-desorption isotherms (b), and pore-size distribution plots obtained from the isotherms (c) from the same samples (XXX values are given in color codes).
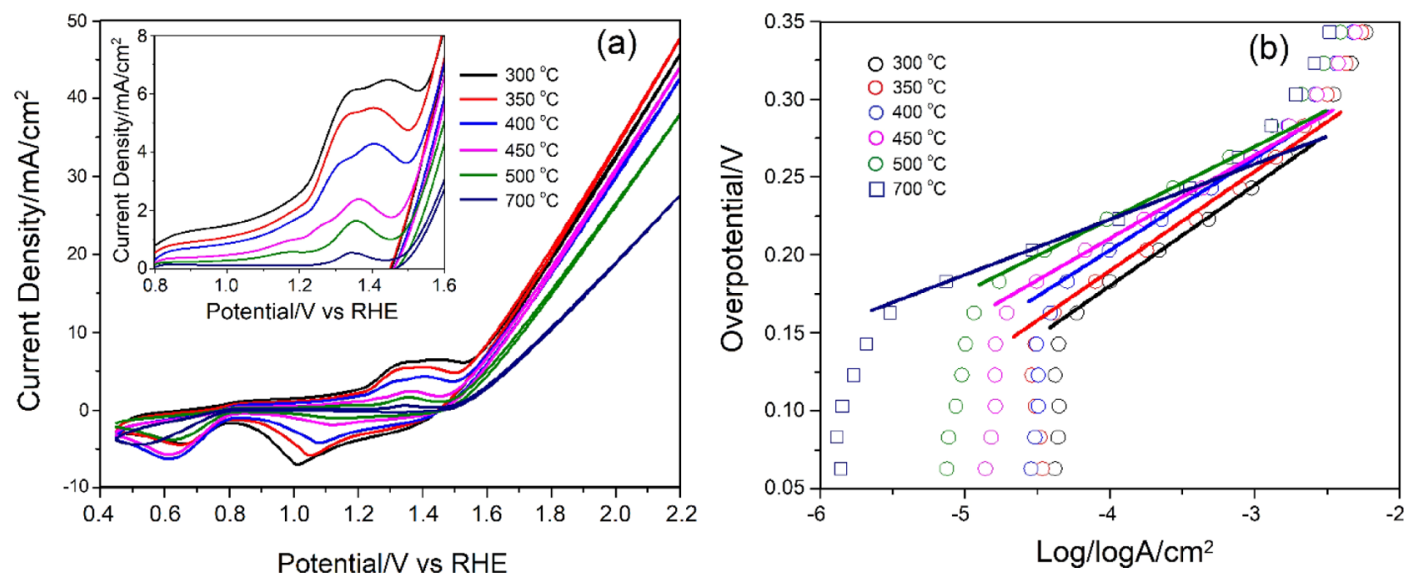

Figure 7. (a) CV curves of $\mathrm{m}-\mathrm{NiCo}_{2} \mathrm{O}_{4}-10-\mathrm{XXX}\left(5^{\text {th }}\right.$ cycle, $\mathrm{XXX}$ is the annealing temperature as color-coded $)$ and (b) Tafel plots of the same samples.

separation was detected, see Figure S4a. The $\mathrm{N}_{2}$ adsorptiondesorption isotherms were in well accord with the XRD results, see Figure $S 4 b, c$. The pore size shows almost no change up to $550{ }^{\circ} \mathrm{C}$ with a relatively smaller pore size, see Figure $\mathrm{S} 4 \mathrm{c}$ and Table 2. Clearly, the $\mathrm{MnCo}_{2} \mathrm{O}_{4}$ domains resist growth upon annealing, as opposed to $\mathrm{NiCo}_{2} \mathrm{O}_{4}$ and $\mathrm{ZnCo}_{2} \mathrm{O}_{4}$ (see later). The SEM image of the samples shows a uniform film morphology at low salt/surfactant ratios (6 to 12) but becomes rougher at higher ratios ( 15 to 25 ), see Figure S5. The cracks are due to film thickness. Note that the thinner films (spin-coated once) are uniform and crack-free. TEM images show a spongelike porous network made of $5-6 \mathrm{~nm} \mathrm{MnCo}_{2} \mathrm{O}_{4}$ particles (see Figure 5b,c).

The $\mathrm{ZnCo}_{2} \mathrm{O}_{4}$ samples were prepared using P123 as the main surfactant and $\mathrm{CTAB}$ as the co-surfactant with a 1:5 P123/ CTAB mole ratio. The P123 system has been investigated at three different compositions, but the intermediate composition (20Zn(II):40Co(II)) yielded a mesoporous thin film with the highest surface area. Therefore, this composition has been investigated more in detail. The $10 \mathrm{Zn}$ (II)/20Co(II)/1P123 samples were also stable both in the mesophase and mesoporous forms. However, high salt samples (30Zn(II)/60Co(II)/ 1P123) were problematic in the gel phase and leached out salt species prior to calcination. Therefore, this composition was only investigated in the gel phase. The mesoporous films were labeled $\mathrm{m}-\mathrm{ZnCo}_{2} \mathrm{O}_{4}-30-\mathrm{XXX}$ and $\mathrm{m}-\mathrm{ZnCo}_{2} \mathrm{O}_{4}-60-\mathrm{XXX}(\mathrm{m}$ stands for mesoporous and 30 and 60 are $(\mathrm{Zn}(\mathrm{II})+2 \mathrm{Co}(\mathrm{II})) /$ $\mathrm{P} 123 \mathrm{~mol}$ ratios and $\mathrm{XXX}$ is the calcination/annealing temperature). Figure 6 shows a set of XRD patterns of m-
$\mathrm{ZnCo}_{2} \mathrm{O}_{4}-60-\mathrm{XXX}$ calcined at various temperatures from 250 to $550{ }^{\circ} \mathrm{C}$. Clearly, all diffraction lines can be indexed to spinel $\mathrm{ZnCo}_{2} \mathrm{O}_{4}$. No other phase or composition was detected in the patterns at all temperatures, see Figure 6a. The only change with increasing temperature was the sharpening of the diffraction lines. Table 1 lists the size of the nanocrystallites making the pore walls, as calculated using Scherrer's equation and the (311) line in the XRD patterns. Figures S6a and S7 show an SEM image of $\mathrm{m}-\mathrm{ZnCo}_{2} \mathrm{O}_{4}-60-400$ and a set of TEM images of $\mathrm{m}$ $\mathrm{ZnCo}_{2} \mathrm{O}_{4}-60-350$ and display a smooth film morphology and uniform pores. The films have disordered sponge-like pores with crystalline pore walls, see Figure S6.

HR-TEM images of $\mathrm{m}-\mathrm{NiCo}_{2} \mathrm{O}_{4}-350, \mathrm{~m}-\mathrm{MnCo}_{2} \mathrm{O}_{4}-350$, and $\mathrm{m}-\mathrm{ZnCo}_{2} \mathrm{O}_{4}-350$ and their analysis are shown in Figure S8. Lattice fringes are clearly visible and spacings between the lattice fringes are consistent with the $d$-spacings of the XRD lines that originated from the (111) planes. Also notice that the size of the crystalline domains on the pore walls $(\sim 9,5$, and $8 \mathrm{~nm}$ in the $\mathrm{m}$ $\mathrm{NiCo}_{2} \mathrm{O}_{4}, \mathrm{~m}-\mathrm{MnCo}_{2} \mathrm{O}_{4}$, and $\mathrm{m}-\mathrm{ZnCo}_{2} \mathrm{O}_{4}$ samples, respectively, compare with the data in Table 1) are similar to that predicted from Scherrer's equation using (111) XRD line broadenings.

Figure $6 \mathrm{~b}, \mathrm{c}$ shows the $\mathrm{N}_{2}$ adsorption-desorption isotherms and pore-size distribution plots, respectively. Isotherms are type IV, characteristic for mesoporous materials. ${ }^{46}$ The pore-size distribution becomes less uniform at higher temperatures but remains more ordered, relatively, compared to $\mathrm{m}-\mathrm{NiCo}_{2} \mathrm{O}_{4}$, synthesized using $\mathrm{C}_{12} \mathrm{E}_{10}$. The pore-size expansion was limited (4-11 nm) in the $\mathrm{m}-\mathrm{ZnCo}_{2} \mathrm{O}_{4}$ samples. We also tested annealing (first calcined at $250{ }^{\circ} \mathrm{C}$ and then annealed at higher 

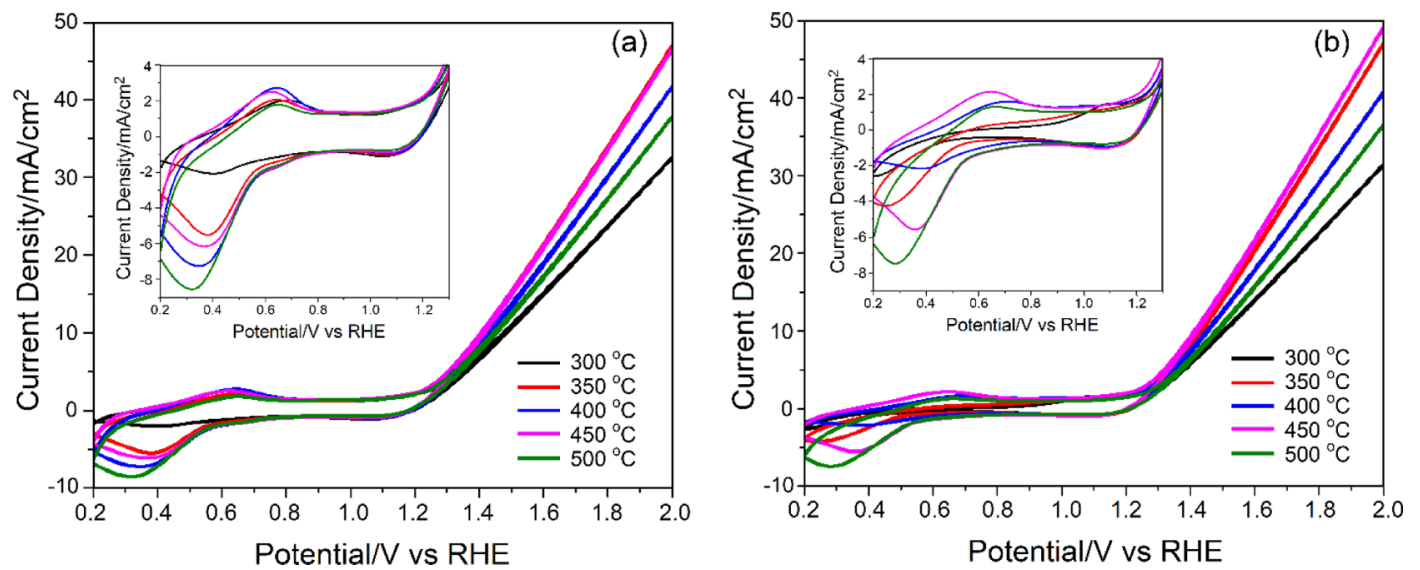

Figure 8. $\mathrm{CV}$ curves of $\mathrm{m}-\mathrm{MnCo}_{2} \mathrm{O}_{4}-10-\mathrm{XXX}$ (XXX values are given in the panels) (a) before and (b) after multistep CP experiments (insets show Faradaic regions of the same $\mathrm{CV}$ curves).

Table 3. Overpotentials $(\eta)$, Tafel Slopes $\left(A_{\mathrm{T}}\right)$, Electrode Resistances $(R)$, and Anodic Charge-Transfer Coefficients $\left(\boldsymbol{\alpha}_{\mathrm{A}}\right)$ of $\mathrm{m}$ $\mathrm{MCo}_{2} \mathrm{O}_{4}(\mathrm{M}=\mathrm{Mn}, \mathrm{Ni}$, and $\mathrm{Zn})$ Electrodes Calcined at Various Temperatures ${ }^{a}$

\begin{tabular}{|c|c|c|c|c|c|c|c|c|c|}
\hline sample & $\eta_{1}^{\mathrm{m}}(\mathrm{mV})$ & $\eta_{1}^{\mathrm{c}}(\mathrm{mV})$ & $\eta_{10}^{\mathrm{m}}(\mathrm{mV})$ & $\eta_{10}^{\mathrm{c}}(\mathrm{mV})$ & $\eta_{100}^{\mathrm{m}}(\mathrm{mV})$ & $\eta_{100}^{c}(\mathrm{mV})$ & $A_{\mathrm{T}}^{\mathrm{m}}(\mathrm{mV} / \mathrm{dec})$ & $R / R_{100}(\Omega)$ & $\alpha_{\mathrm{a}}$ \\
\hline $\mathrm{Ni}-300$ & 204 & 187 & 426 & 253 & 1932 & 202 & 63 & $17.3 / 16.0$ & 0.94 \\
\hline $\mathrm{Ni}-350$ & 215 & 201 & 404 & 268 & 1594 & 234 & 59 & $13.6 / 12.6$ & 1.00 \\
\hline $\mathrm{Ni}-400$ & 210 & 193 & 398 & 227 & 1905 & 193 & 60 & $17.1 / 15.8$ & 0.99 \\
\hline $\mathrm{Ni}-450$ & 222 & 205 & 423 & 251 & 1905 & 185 & 54 & $17.2 / 15.8$ & 1.10 \\
\hline $\mathrm{Ni}-500$ & 224 & 206 & 558 & 377 & 2236 & 426 & 49 & $18.1 / 19.1$ & 1.21 \\
\hline $\mathrm{Ni}-700$ & 251 & 228 & 657 & 425 & 2810 & 490 & 53 & $23.2 / 24.5$ & 1.12 \\
\hline Mn-300 & 238 & 217 & 525 & 316 & 2455 & 365 & 62 & $20.9 / 20.9$ & 0.95 \\
\hline $\mathrm{Mn}-350$ & 241 & 227 & 440 & 300 & 1783 & 383 & 75 & $14.0 / 13.9$ & 0.79 \\
\hline $\mathrm{Mn}-400$ & 247 & 230 & 456 & 291 & 2020 & 370 & 78 & $16.5 / 16.2$ & 0.76 \\
\hline $\mathrm{Mn}-450$ & 242 & 228 & 431 & 293 & 1748 & 368 & 84 & $13.8 / 13.4$ & 0.70 \\
\hline $\mathrm{Mn}-500$ & 254 & 237 & 473 & 300 & 2103 & 373 & 85 & $17.3 / 16.8$ & 0.70 \\
\hline $\mathrm{Zn}-300$ & 250 & 232 & 496 & 318 & 2141 & 361 & 59 & $17.8 / 17.7$ & 1.00 \\
\hline $\mathrm{Zn}-350$ & 264 & 251 & 430 & 300 & 1645 & 345 & 54 & $13.0 / 12.7$ & 1.10 \\
\hline $\mathrm{Zn}-400$ & 256 & 239 & 490 & 316 & 2098 & 358 & 60 & $17.4 / 17.2$ & 0.99 \\
\hline $\mathrm{Zn}-500$ & 244 & 228 & 504 & 343 & 2013 & 403 & 55 & $16.1 / 16.6$ & 1.08 \\
\hline
\end{tabular}

${ }^{a}$ Overpotentials: ${ }^{\mathrm{m}}$ (measured from $2 \mathrm{~h}$ and multistep CP experiments) and ${ }^{\mathrm{c}}$ (calculated after IR compensation using multistep CP data). $R_{100}$ is the predicted electrode resistance at $100 \mathrm{~mA} / \mathrm{cm}^{2}$ current density.

temperatures) versus direct calcination at a given temperature to establish a simple method. Both sets gave similar isotherms and pore-size distribution plots, see Figures $6 \mathrm{c}$ and S6b. However, the direct calcination at 300,350 , and $400{ }^{\circ} \mathrm{C}$ yields a more uniform pore-size distribution that may be necessary for certain applications, compare Figures $6 \mathrm{c}$ and S6b.

We also checked the $60(\mathrm{Ni}(\mathrm{II})+2 \mathrm{Co}(\mathrm{II}) / \mathrm{P} 123$ sample to determine if the surfactant plays a role in the order of mesopores. Figure S9 shows a set of PXRD patterns, $\mathrm{N}_{2}$ adsorptiondesorption isotherms, and pore-size distribution plots of $\mathrm{m}$ $\mathrm{NiCo}_{2} \mathrm{O}_{4}-60-\mathrm{XXX}$ samples. The XRD patterns, $\mathrm{N}_{2}$ adsorptiondesorption isotherms, and pore-size distribution plots are all remarkably similar to those of samples prepared using $\mathrm{C}_{12} \mathrm{E}_{10}$ mesophases. Similarly, the $\mathrm{NiO}$ phase appears at high-annealing temperatures and pores become disordered and large; the surface area is $175 \mathrm{~m}^{2} / \mathrm{g}$ at $250{ }^{\circ} \mathrm{C}$, but it gradually decreases to $25 \mathrm{~m}^{2} / \mathrm{g}$ at $500{ }^{\circ} \mathrm{C}$, and similarly the pores expand from 3.9 to $15.4 \mathrm{~nm}$ at those temperatures. We can therefore conclude that the surfactant type is not as important for these materials.

Electrochemical Properties of $\mathrm{m}-\mathrm{MCo}_{2} \mathrm{O}_{4}(\mathrm{M}=\mathrm{Mn}(\mathrm{II})$, $\mathrm{Ni}(\mathrm{II})$, and $\mathrm{Zn}(\mathrm{II})$ ) Thin Films. The electrodes of $\mathrm{m}-\mathrm{NiCo}_{2} \mathrm{O}_{4}$, $\mathrm{m}-\mathrm{MnCo}_{2} \mathrm{O}_{4}$, and $\mathrm{m}-\mathrm{ZnCo}_{2} \mathrm{O}_{4}$ were prepared by spin-coating their freshly prepared solutions at their optimum compositions over a $1 \times 1 \mathrm{~cm}^{2}$ FTO substrate. The calcined films were then used as the WE in all electrochemical characterization and the OER. Figure $7 \mathrm{a}$ shows a set of cyclic voltammograms (CV curves) of the $\mathrm{m}-\mathrm{NiCo}_{2} \mathrm{O}_{4}$ electrodes, calcined at indicated temperatures. Figure $8 \mathrm{~b}$ shows the Tafel plots of the same electrodes. The Tafel slope $\left(\mathrm{A}_{\mathrm{T}}\right)$ gradually decreases from 63 to $49 \mathrm{mV} / \mathrm{dec}$ by increasing the annealing temperature, see Figure $7 \mathrm{~b}$ and Table 3. Clearly, with increasing calcination/annealing temperature, the peak currents of the Faradaic process decrease and accord well with the reduced surface area of the electrodes. A typical electrode has a mass of $0.1 \mathrm{mg} /$ electrode. Such a high current density observed in the Faradaic process is an indication of the accessibility of the pore surface (internal surface) of $\mathrm{m}$ $\mathrm{NiCo}_{2} \mathrm{O}_{4}$ electrodes. The peak at around $-0.2 \mathrm{~V}$ has been previously assigned to the $\mathrm{NiO}$ phase $\left(\mathrm{Ni}^{2+} / \mathrm{Ni}^{3+}\right) .{ }^{38}$ Later peaks at higher potentials are due to other $\mathrm{Ni}^{2+} / \mathrm{Ni}^{3+}, \mathrm{Ni}^{3+} / \mathrm{Ni}^{4+}$, and $\mathrm{Co}^{3+} / \mathrm{Co}^{4+}$ oxidation processes over the electrode surfaces, see the inset in Figure 7a. Although surface-active species, they are likely the active species for the OER process, which gradually decreases with increasing annealing temperature (with decreasing surface area), the slope of the OER process (over $1.4 \mathrm{~V}$ ) 
increases at $350{ }^{\circ} \mathrm{C}$ with almost no change up to $500{ }^{\circ} \mathrm{C}$. If we normalize our $\mathrm{CV}$ curves to the surface area of the actual electrodes (by dividing the current density to the surface area of a $0.1 \mathrm{mg}$ electrode to compensate the reduced surface area at higher temperatures), the current density gradually increases with increasing temperature (crystallization), see Figure S9; the current densities are $1.88,3.94,4.99,6.64$, and $8.47 \mathrm{~A} / \mathrm{m}^{2}$ at 300 , $350,400,450$, and $500{ }^{\circ} \mathrm{C}$ at $2.0 \mathrm{~V}$ versus RHE, respectively. The current density increases linearly with increasing annealing temperature, like the particle size and crystallinity, see the inset in Figure S10. The normalized CV curves also demonstrate that not only the surface area but also the crystallinity of the pore walls is important in the OER. Therefore, the ideal targeted electrodes should have a high surface area with high crystallinity. The overpotential values evaluated from the long-term CP experiments (see Figure $\mathrm{S} 11 \mathrm{a}, \mathrm{b}$ ) are lower than those of both $\mathrm{NiO},{ }^{38} \mathrm{Co}_{3} \mathrm{O}_{4}{ }^{47}$ and other spinel-transition-metal oxides (see Table S2). ${ }^{17,48-56}$

The $\mathrm{m}-\mathrm{NiCo}_{2} \mathrm{O}_{4}$ electrodes have also been used for $\mathrm{CP}$ experiments at 1 and $10 \mathrm{~mA} / \mathrm{cm}^{2}$ current densities for $2 \mathrm{~h}$ each and for multistep CP experiments for a duration of $30 \mathrm{~min}$ at each current density starting from 10 to $100 \mathrm{~mA} / \mathrm{cm}^{2}$ with 10 $\mathrm{mA}$ increments for $5.5 \mathrm{~h}$, see Figure S1 1a,b. Potential (calculated using $V_{\mathrm{I}}-A_{\mathrm{T}} \log (j)$, where $V_{\mathrm{I}}$ is the potential at each current density $(j), A_{\mathrm{T}}$ is the Tafel slope, and $j$ is the current density, obtained from multistep CP experiments) versus current density is linear, where the slope is the resistance of the electrode $(\mathrm{R})$, see Figure $S 11 \mathrm{c}$. $\mathrm{R}$ is equal to $\left(V_{100}-V_{10}-A_{\mathrm{T}}\right) / \Delta I$ (where 10 to $100 \mathrm{~mA}$ is a decade, $\Delta I=90 \mathrm{~mA}$, and $V_{100}$ and $V_{10}$ are potentials at 100 and $10 \mathrm{~mA} / \mathrm{cm}^{2}$ current densities, respectively), see Table 3 and Figure S9c. Also, note that the electrode resistance predominantly originates from the FTO substrate. The resistance of $\mathrm{m}-\mathrm{NiCo}_{2} \mathrm{O}_{4}-10-300$ is 17.3 and of $\mathrm{m}-\mathrm{NiCo}_{2} \mathrm{O}_{4}$ $10-350$ is $13.6 \Omega$, see others in Table 3. Clearly, the IR drop is the lowest in the $\mathrm{m}-\mathrm{NiCo}_{2} \mathrm{O}_{4}-10-350$ electrode that displays the best OER performance.

The CV curves before and after long-term CP experiments were also recorded to monitor the stability of the electrodes and any change in the surface chemical species. Figure S12 compares $\mathrm{CV}$ curves before and after multistep CP experiments. Clearly, the peak current at around $1.1 \mathrm{~V}$ increases after the $\mathrm{CP}$ experiments. This peak has also been observed in mesoporous $\mathrm{NiO}$ after $\mathrm{CP}$ experiments. The $\mathrm{NiO}$ surface is covered with $\mathrm{NiOOH} / \mathrm{Ni}(\mathrm{OH})_{2}$ surface species. The peak at $1.1 \mathrm{~V}$ has been assigned to the oxidation of $\mathrm{Ni}(\mathrm{OH})_{2}$ to $\mathrm{NiOOH}$ species $\left(\mathrm{Ni}^{2+} /\right.$ $\left.\mathrm{Ni}^{3+}\right)^{38}$ and is consistent with the XRD pattern, which also displays $\mathrm{NiO}$ lines in the $\mathrm{m}-\mathrm{NiCo}_{2} \mathrm{O}_{4}$ electrodes. The peak(s) at higher potentials (around 1.3 V vs RHE) could be assigned to the oxidation of $\mathrm{Ni}^{3+}$ and $\mathrm{Co}^{3+}$ species to their $4+$ species, which are the active species in the OER process. ${ }^{38,39}$ It has been demonstrated previously that the rock salt $\mathrm{NiO}$ is converted to a $\mathrm{NiO}-\mathrm{NiOOH}$ core-shell structure. The $\mathrm{NiOOH}$ layer is converted, upon reverse cycling (reduction process), to layered $\mathrm{Ni}(\mathrm{OH})_{2}$, which is more active than $\mathrm{NiO}$. Under harsh oxidation conditions (such as at $100 \mathrm{~mA} / \mathrm{cm}^{2}$ current density), more active surface species are produced over the $\mathrm{m}-\mathrm{NiCo}_{2} \mathrm{O}_{4}$ electrode surface; as a result, the electrodes work at relatively lower overpotentials. Notice that the overpotentials at $100 \mathrm{~mA} /$ $\mathrm{cm}^{2}$ current density, after a correction by subtracting the IR drop $\left(\eta_{100}\right.$, calculated in Table 3$)$, are even lower than the ones at 1 $\mathrm{mA} / \mathrm{cm}^{2}$ current density in $\mathrm{m}-\mathrm{NiCo}_{2} \mathrm{O}_{4}-10-\mathrm{XXX}(\mathrm{XXX}$ is 300 , 350,400 , and $450{ }^{\circ} \mathrm{C}$ ) but are reasonable in the samples annealed at higher temperatures $\left(500\right.$ and $\left.700{ }^{\circ} \mathrm{C}\right)$, see Table 3 .
Since the overpotential could not be lower at higher current densities, the actual electrode resistance must decrease with use in the OER at higher current densities; the electrode becomes a better conductor. If we assume that the overpotential increases by $2 A_{\mathrm{T}}$ by increasing the current density from 1 to $100 \mathrm{~mA} / \mathrm{cm}^{2}$, then the actual overpotential must be at least $330 \mathrm{mV}$ in the $\mathrm{m}$ $\mathrm{NiCo}_{2} \mathrm{O}_{4}-10-300$ electrode. However, the measured overpotential is $1932 \mathrm{mV}$ for this electrode, due to overpotential $(330 \mathrm{mV})$ plus IR drop $(1620 \mathrm{~V})$. Therefore, the electrode resistance is $16.2 \Omega$ (calculated using Ohm's law, $R=\left(V_{100}-\right.$ $\left.V_{\mathrm{o}}\right) / 100$, where $V_{100}$ is the measured potential $(1932 \mathrm{mV})$ and $V_{\mathrm{o}}(330 \mathrm{mV})$ is the calculated overpotential at $100 \mathrm{~mA} / \mathrm{cm}^{2}$ current density) or lower after the multistep CP experiment. Table 3 lists the electrode resistances together with the resistance after the $\mathrm{CP}$ experiment to demonstrate that all electrodes display lower resistance and better performance with use for OER at high current densities.

Similar electrochemical data have also been collected using $\mathrm{m}$ $\mathrm{MnCo}_{2} \mathrm{O}_{4}-10$ electrodes. Figure 8a shows a set of CV curves of $\mathrm{m}-\mathrm{MnCo}_{2} \mathrm{O}_{4}-10$ electrodes, calcined at five different temperatures. The $\mathrm{m}-\mathrm{MnCo}_{2} \mathrm{O}_{4}-10-350$ electrode performs the best in the OER, but the other electrodes, calcined at higher temperatures, also display a similar performance. As previously shown by the XRD patterns and $\mathrm{N}_{2}$ adsorption-desorption isotherms, the $\mathrm{m}-\mathrm{MnCo}_{2} \mathrm{O}_{4}$ samples resist heat treatments. The $\mathrm{CV}$ curves and OER performance of these electrodes are also similar. Overpotential values are slightly higher than those of $\mathrm{m}$ $\mathrm{NiCo}_{2} \mathrm{O}_{4}$ electrodes, but the $A_{\mathrm{T}}$ values are clearly higher, see Table 3 and Figure S13; they increase with increasing annealing temperature. For instance, the $A_{\mathrm{T}}$ value of the m- $\mathrm{MnCo}_{2} \mathrm{O}_{4}-10$ 300 electrode is like that of $\mathrm{m}-\mathrm{NiCo}_{2} \mathrm{O}_{4}$ electrodes, but it gradually increases up to $85 \mathrm{mV} / \mathrm{dec}$ in $\mathrm{m}-\mathrm{MnCo}_{2} \mathrm{O}_{4}-10-500$, indicating a change in the OER mechanism and likely the surface chemistry. We also performed the CP experiments at 1 and 10 $\mathrm{mA} / \mathrm{cm}^{2}$ current densities for a duration of $2 \mathrm{~h}$ each and multistep CPs starting from 10 to $100 \mathrm{~mA} / \mathrm{cm}^{2}$ with a $10 \mathrm{~mA}$ increment for $30 \mathrm{~min}$ at each current density for another $5.5 \mathrm{~h}$, see Figure S14a,b. The electrode resistance has been evaluated using the multistep CP data and by considering the change in the Tafel slopes, see Figure S14c and Table 3. Clearly, the change in $\mathrm{R}$ is negligible in the $\mathrm{m}-\mathrm{MnCo}_{2} \mathrm{O}_{4}-10-\mathrm{XXX}$ electrodes with use under harsh conditions (high current densities), indirectly indicating the electrode stability. Moreover, the CV curves after $\mathrm{CP}$ experiments were also recorded to check the stability of the electrodes and investigate the chemical changes on the electrode surfaces, see Figure $8 \mathrm{~b}$. The $\mathrm{m}-\mathrm{MnCo}_{2} \mathrm{O}_{4}-10-300$ electrode shows a significant/visible change in the $\mathrm{CV}$ curve after the multistep CP experiment. Also note that this electrode has the highest resistance $(23.8 \mathrm{Ohms})$ and the lowest Tafel slope. The peak observed at around $0.72 \mathrm{~V}$, likely due to the oxidation of $\mathrm{Mn}^{2+}$ to $\mathrm{Mn}^{3+}$, almost disappears, and a new peak at around 1.1 $\mathrm{V}$ forms due to the oxidation of $\mathrm{Mn}^{3+}$ to $\mathrm{Mn}^{4+}$ or of $\mathrm{Co}^{3+}$ to $\mathrm{Co}^{4+}$; however, the change in $\mathrm{CV}$ curves is less in the $\mathrm{m}-\mathrm{MnCo}_{2} \mathrm{O}_{4}-10$ 350 electrode and almost none in all other electrodes, calcined above $400{ }^{\circ} \mathrm{C}$. Likely, at low temperatures, there is some $\mathrm{Mn}^{2+}$ species on the electrode surface and eliminated during the $\mathrm{CP}$ experiment over the $\mathrm{m}-\mathrm{MnCo}_{2} \mathrm{O}_{4}-10-300$ electrode. The $\mathrm{Mn}^{2+}$ species (maybe in the form of $\mathrm{MnO}$ ) at low temperatures is dissolved during long-term CP experiments; however, $\mathrm{Mn}^{2+}$ in the spinel structure resists solvation. This behavior is also visible in $A_{\mathrm{T}}$ values; the $A_{\mathrm{T}}$ is like $\mathrm{Co}_{3} \mathrm{O}_{4}$ at low temperatures $(62 \mathrm{mV} /$ dec, maybe indicating more $\mathrm{Co}^{3+}$ species by dissolving $\mathrm{Mn}^{2+}$ species over the $\mathrm{m}-\mathrm{MnCo}_{2} \mathrm{O}_{4}-10-300$ electrode surface), but it 

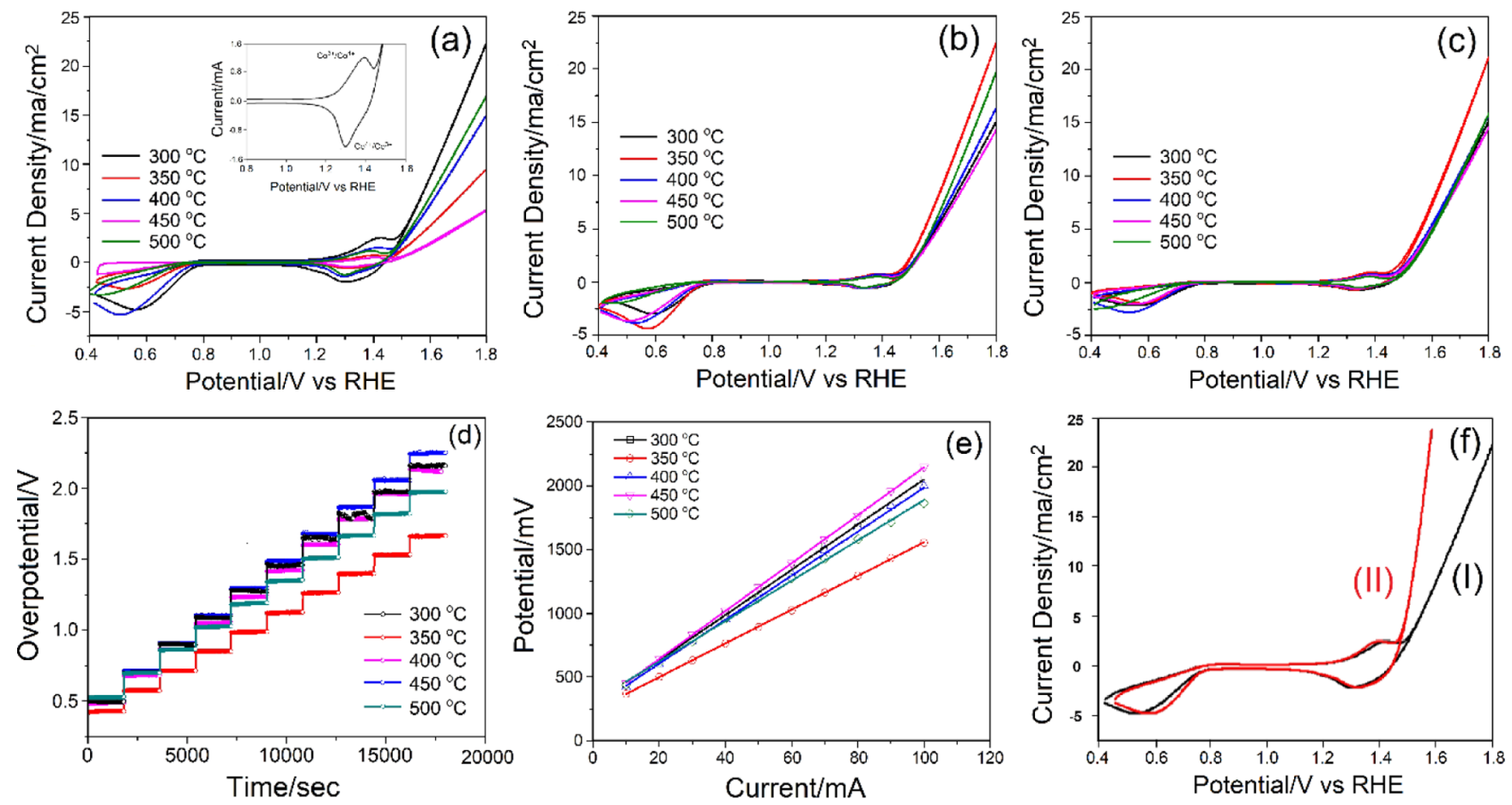

Figure 9. $\mathrm{CV}$ curves of (a) annealed $\mathrm{m}-\mathrm{ZnCo}_{2} \mathrm{O}_{4}-60$-an and directly calcined $\mathrm{m}-\mathrm{ZnCo}_{2} \mathrm{O}_{4}-60-d$ before (b) and after (c) multistep CP experiments, (d) multistep CP, (e) potential versus current plot, and (f) CV curves before and after subtracting the IR drop.

increases to the $78-85 \mathrm{mV} / \mathrm{dec}$ range after annealing the electrodes over $400{ }^{\circ} \mathrm{C}$. As suggested in our previous work on $\mathrm{LiMn}_{2-x} \mathrm{Co}_{x} \mathrm{O}_{4}$ electrodes, ${ }^{38}$ such as $\mathrm{Mn}^{2+}$ and $\mathrm{Co}^{3+}$, the surface species collectively work in the OER process. It has been well established that pure $\mathrm{LiMn}_{2} \mathrm{O}_{4}$ (manganese is $\mathrm{Mn}^{3+}$ and $\mathrm{Mn}^{4+}$ ) is not stable in electrochemical processes due to disproportionation reactions $\left(2 \mathrm{Mn}^{3+}\right.$ species undergo disproportionation to $\mathrm{Mn}^{2+}$ and $\mathrm{Mn}^{4+}$ species and dissolution of $\mathrm{Mn}^{2+}$ sides); ${ }^{57}$ however, the presence of cobalt stabilizes the manganesecobalt-oxide surface species and synergistically (electronic) work together in the OER process. ${ }^{39}$ Also notice that the electrode stability is also reflected in the overpotential values after IR compensation. The overpotential increases as a function of logarithm of $A_{\mathrm{T}}$ with increasing current density. The electrode resistance, after the multistep CP experiment, changes little. Although the overpotential values are slightly higher with a slower OER rate in $\mathrm{m}-\mathrm{MnCo}_{2} \mathrm{O}_{4}$ electrodes, they are more stable and resistive to heat treatments. Thermal stability also brings electrochemical stability to these electrodes.

The CV curves of both set of $\mathrm{m}-\mathrm{ZnCo}_{2} \mathrm{O}_{4}$ samples (calcined at $250{ }^{\circ} \mathrm{C}$, then annealed at different temperatures, and directly calcined at the tested temperature, and labeled $\mathrm{m}-\mathrm{ZnCo}_{2} \mathrm{O}_{4}$-an and $\mathrm{m}-\mathrm{ZnCo}_{2} \mathrm{O}_{4}-d$, respectively) were also obtained and are displayed in Figure 9. The only peak at around $1.4 \mathrm{~V}$ is due to the oxidation of $\mathrm{Co}^{3+}$ to $\mathrm{Co}^{4+}$, see the inset in Figure 9a. No trend was observed in the annealed electrodes in terms of stability and OER performance. However, the directly calcined $\mathrm{m}-\mathrm{ZnCo}_{2} \mathrm{O}_{4}-$ $d$ electrodes show excellent stability in long-term use at high current densities in the oxygen evolution process. Note that all the electrodes were fabricated using the salt/P123 mole ratio of 60. Since there is a trend in OER performance and the electrodes are stable to long-term $\mathrm{CP}$ experiments, the $\mathrm{m}-\mathrm{ZnCo}_{2} \mathrm{O}_{4}$ - $d$ samples were also investigated in detail. Figure $9 \mathrm{~b}$ shows the $\mathrm{CV}$ curves of the freshly prepared electrodes. Like the $\mathrm{m}-\mathrm{NiCo}_{2} \mathrm{O}_{4}$ 10-350 and $\mathrm{m}-\mathrm{MnCo}_{2} \mathrm{O}_{4}-10-350$ electrodes, the directly calcined $\mathrm{m}-\mathrm{ZnCo}_{2} \mathrm{O}_{4}-d-350$ displays the best electrode performance among the five electrodes prepared at 300, 350, 400, 450, and $500{ }^{\circ} \mathrm{C}$. Moreover, the $\mathrm{m}-\mathrm{ZnCo}_{2} \mathrm{O}_{4}-d-500$ electrode performs as good as the $\mathrm{m}-\mathrm{ZnCo}_{2} \mathrm{O}_{4}$ - $d-350$ electrode in longterm $\mathrm{CP}$ tests. Comparing all three electrodes, $\mathrm{m}-\mathrm{MCo}_{2} \mathrm{O}_{4}-n$ 350 (where $\mathrm{M}$ is $\mathrm{Ni}$ and $\mathrm{Mn}, n$ is 10 ; for $\mathrm{M}$ is $\mathrm{Zn}, n$ is 60 ), it appears that $350{ }^{\circ} \mathrm{C}$ is an ideal calcination temperature to fully evacuate the pores and make the internal surface accessible for the electrochemical process. Figure $9 \mathrm{c}$ shows the CV curves after multistep $\mathrm{CP}$ experiments and shows the stability of the $\mathrm{m}$ $\mathrm{ZnCo}_{2} \mathrm{O}_{4}-d$-XXX electrodes. All electrodes displayed almost identical $\mathrm{CV}$ curves after long-term use under harsh conditions. Interestingly, some electrodes performed even better after used in the CP experiment. For example, both $\mathrm{m}-\mathrm{ZnCo}_{2} \mathrm{O}_{4}-d$ and $\mathrm{m}$ $\mathrm{ZnCo}_{2} \mathrm{O}_{4}$-an electrodes, calcined directly at and annealed to 500 ${ }^{\circ} \mathrm{C}$, respectively, improved the most. This shows that the crystallinity of the electrodes is particularly important to further improve the OER performance of the electrodes. The $A_{\mathrm{T}}$ values of $\mathrm{m}-\mathrm{ZnCo}_{2} \mathrm{O}_{4}$ electrodes fluctuate at around $52-60 \mathrm{mV} / \mathrm{dec}$, like in the $\mathrm{m}-\mathrm{NiCo}_{2} \mathrm{O}_{4}$ electrodes (see Table 3 and Figure $\mathrm{S} 15 \mathrm{a}$ ). Figures $\mathrm{S} 15 \mathrm{~b}$ and $9 \mathrm{~d}$ show the CPs at 1 and multistep CPs from 10 to $100 \mathrm{~mA} / \mathrm{cm}^{2}$ current densities, respectively. The CP data can be used to determine the electrode resistances, which are the slope of the potentials (determined at each current density, 10 to $100 \mathrm{~mA}$ in multistep CP plots by subtracting the contribution of $A_{\mathrm{T}}$ ) versus current density plots, see Figure 9e. After subtracting the IR drop values, the electrode overpotentials drop to 226, 280 , and $345 \mathrm{mV}$ at 1,10 , and $100 \mathrm{~mA} / \mathrm{cm}^{2}$ current densities, respectively, in the $\mathrm{m}-\mathrm{ZnCo}_{2} \mathrm{O}_{4}-d-350$ electrode with increments of 54 and $55 \mathrm{mV}$ close to $A_{\mathrm{T}}(54 \mathrm{mV} / \mathrm{dec})$, see Table 3 . However, if we assume that the reaction mechanism and the reaction rate (Tafel slope) do not change during the multistep CP experiment, then the calculated $\Delta R$ varies within $1.0 \Omega$, indicating high stability of the electrodes under harsh conditions. The major losses, at high current densities, are due 


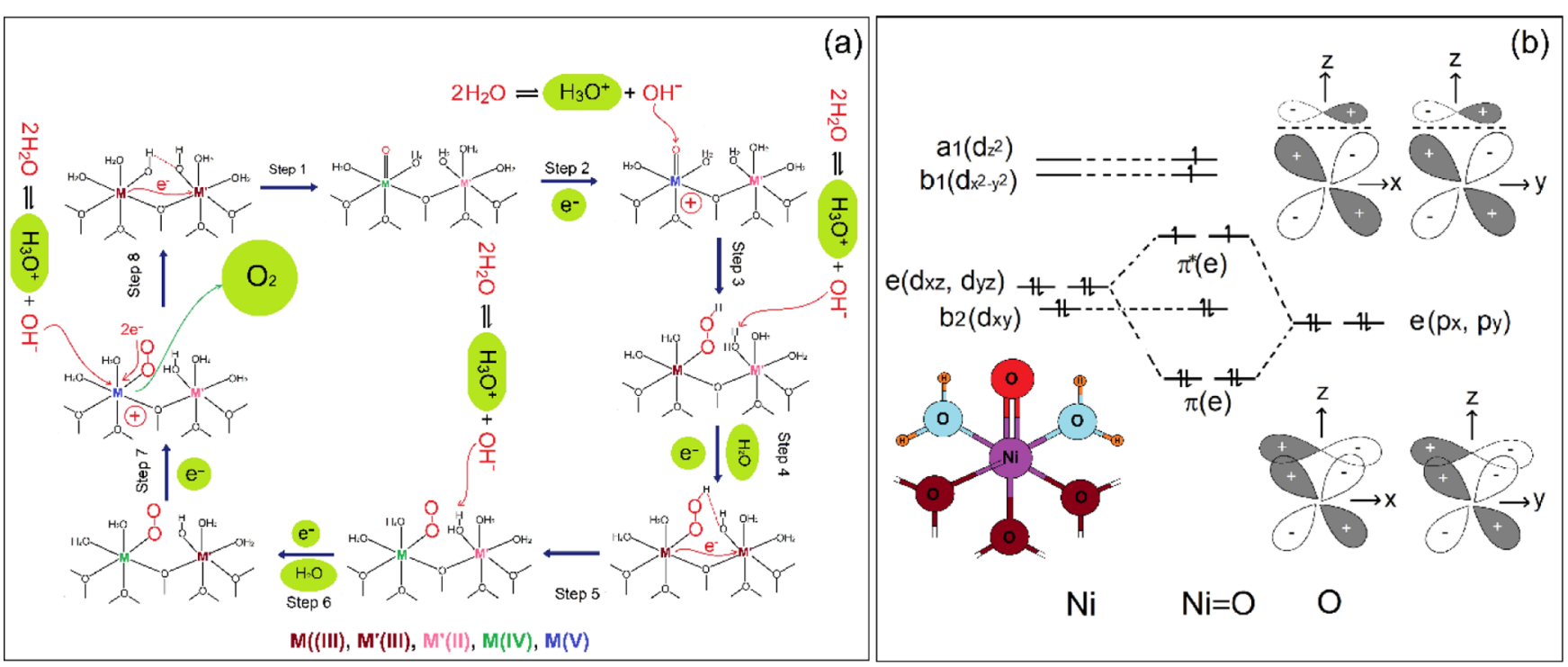

Figure 10. Suggested eight-step OER mechanism and (b) MO energy level diagram, showing the $\mathrm{M}-\mathrm{O} \pi$-interaction in $\mathrm{NiO}_{6}$-octahedral species.

to IR drops that can be mostly overcome using better conductive substrates, such as carbon or metals. Figure 9f shows two CV curves before and after IR correction, showing a sharp increase in the current density over the potentials at which the OER process takes place and is consistent with the Tafel slope.

We also performed a CA experiment to determine the Faradaic efficiency of the best-performing electrodes, namely, $\mathrm{m}-\mathrm{NiCo}_{2} \mathrm{O}_{4}-350, \mathrm{~m}-\mathrm{MnCo}_{2} \mathrm{O}_{4}-350$, and $\mathrm{m}-\mathrm{ZnCo}_{2} \mathrm{O}_{4}-350$. The produced $\mathrm{O}_{2}$ amount was determined using GC, see Table S3. Both $\mathrm{m}-\mathrm{NiCo}_{2} \mathrm{O}_{4}-350$ and $\mathrm{m}-\mathrm{ZnCo}_{2} \mathrm{O}_{4}$ electrodes perform better with use; their Faradaic efficiency reaches 92 and $73 \%$, respectively, in $30 \mathrm{~min}$. However, the $\mathrm{m}-\mathrm{MnCo}_{2} \mathrm{O}_{4}$ displays over 93\% Faradaic efficiency in $10 \mathrm{~min}$.

OER Mechanism over the $\mathrm{m}-\mathrm{MCo}_{2} \mathrm{O}_{4}(\mathrm{M}=\mathrm{Ni}, \mathrm{Mn}$, and $\mathrm{Zn}$ ) Electrodes. The OER mechanism, suggested in our previous work, ${ }^{39}$ is modified and updated in Figure 10a. Originally, Wang et al. ${ }^{58,59}$ suggested a six-step OER mechanism based on a nucleophilic acid-base reaction that considers a nucleophilic attack of hydroxide in the medium to metal oxo ( $\mathrm{M}$ $=\mathrm{O}$, formed either by oxidation or reaction of two metal hydroxides, see Figure 10a) species to form a $\mathrm{O}-\mathrm{O}$ bond. The mechanism is based on the electroneutrality principle, electronegativity of the likely surface species, and some experimental evidence. The electronegativity difference between two metals (indicated as $\mathrm{M}$ and $\mathrm{M}^{\prime}$ ) is the driving force for the first and second steps (formation of $\mathrm{M}=\mathrm{O}$ and nucleophilic attack of the hydroxide ion to the metal oxo side for the $\mathrm{O}-\mathrm{O}$ bond formation, $\mathrm{M}-\mathrm{OOH}$ ). Also, the high affinity for water (as evidenced from DFT calculations ${ }^{59}$ ) to the $\mathrm{M}^{\prime}$ side synergistically amplifies the OER. Also, note that the formation of $\mathrm{M}=\mathrm{O}$, $\mathrm{M}-\mathrm{OOH}$, and superoxide $\left(\mathrm{O}_{2}^{-}\right)$has also been identified by in situ ATR-FTIR studies during the electrochemical process and/ or later analysis of the used metal oxide electrodes. ${ }^{60-63}$

A qualitative molecular orbital (MO) energy level diagram, which would be useful to understand the formation and role of the metal-oxygen double bond (metal-oxo bond, $\mathrm{M}=\mathrm{O}$ ) was constructed using metal $d$-orbitals and oxygen $2 \mathrm{p}_{x}$ and $2 \mathrm{p}_{y}$ orbitals, see Figure $10 \mathrm{~b}$. The MO diagram has been constructed by perturbing the local symmetry from octahedral to the $C_{4 v}$ point group by the formation of $\mathrm{M}=\mathrm{O}$ along the $\mathrm{z}$-axis, see the structure in Figure 10b. A partially or fully occupied doubly degenerate $e\left(d_{x z}\right.$ and $\left.d_{y z}\right)$ orbitals of $M$ interact with the occupied $\mathrm{e}\left(2 \mathrm{p}_{x}\right.$ and $\left.2 \mathrm{p}_{y}\right)$ orbitals of oxo-oxygen, where the $\mathrm{M}=$ $\mathrm{O} \pi$-bond strength is enhanced. Moreover, the electron donation from oxygen to the metal side also enhances the electrophilic character of the oxo-oxygen. Also, note that the strength of the $\pi-\pi$ interaction in the metal-oxo bond strongly depends on the electronegativity difference between the metal ion (which increases by oxidation to higher oxidation states) and the oxygen atom. Therefore, the formation of the M(IV) or $\mathrm{M}(\mathrm{V})$ side is important in the electrochemical process to increase the electrophilicity of $\mathrm{M}=\mathrm{O}$ sides. Simply, a strong $\pi$ interaction pushes the $\pi^{*} \mathrm{e}\left(\mathrm{d}_{x z}, \mathrm{~d}_{y z}\right)$ orbitals to higher energy and makes the complex high spin and half-filled in electron-rich systems such as $\mathrm{Ni}$ and $\mathrm{Co}$, see Figure $10 \mathrm{~b}$. The calculated $\pi$ bond order using electrons of bonding $(\pi)$ and antibonding $\left(\pi^{*}\right)$ orbitals for the oxo bond is 1.0 for $\mathrm{d}^{3} \mathrm{Mn}(\mathrm{IV}), 1.5$ for $\mathrm{d}^{2} \mathrm{Mn}(\mathrm{V})$, 1.0 for $\mathrm{d}^{5} \mathrm{Co}(\mathrm{IV})$, and 1.0 for $\mathrm{d}^{6} \mathrm{Ni}(\mathrm{IV})$ in their oxo species. This simple prediction accords well with our findings that all spinels, investigated in this work, perform well and in a similar manner. The suggested OER mechanism is similar to our previous proposal for the mesoporous $\mathrm{LiMn}_{2-x} \mathrm{Co}_{x} \mathrm{O}_{4}$ thin-film electrodes. ${ }^{39}$ Also notice that $\mathrm{m}-\mathrm{MCo}_{2} \mathrm{O}_{4}$ and $\mathrm{LiMn}_{2-x} \mathrm{Co}_{x} \mathrm{O}_{4}$ have spinel structures and likely have similar surface species. Briefly, water dissociation is an important process, where a hydroxide ion is used either for a nucleophilic attack to $\mathrm{M}=\mathrm{O}$ or as a base to undergo an exchange reaction with coordinated water in necessary steps (inspect Figure 10a), as a result to produce hydronium ions $\left(\mathrm{H}_{3} \mathrm{O}^{+}\right)$in steps $2,3,6$, and 8 ; hydronium ions are necessary for the counter electrode reaction. $M$ and $M^{\prime}$ simultaneously undergo oxidation reactions to produce the necessary four electrons in steps 2, 4, 6, and 7 and a selfreduction to produce an oxo bond in step 1 , a superoxide in step 5 , and an oxygen molecule in step 8 in an overall water-splitting process.

To bring some insights into the suggested proposal, we also obtained high-resolution XPS spectra of O 1s, Mn 2p, Co 2p, Ni $2 \mathrm{p}$, and $\mathrm{Zn} 2 \mathrm{p}$ regions before and after multistep CP experiments by directly using the coated FTO electrodes (top surface) and ground electrodes (internal pore surface) to determine the differences in the electrode surface and internal surface. Figure S16 shows a set of metal $2 \mathrm{p}\left({ }^{2} \mathrm{P}_{3 / 2}\right.$ region $)$ high-resolution XPS 
spectra of the FTO top surface and the internal surface of $\mathrm{m}$ $\mathrm{MCo}_{2} \mathrm{O}_{4}-350(\mathrm{M}$ is $\mathrm{Ni}, \mathrm{Mn}$, and $\mathrm{Zn}$ ) electrodes before and after CP experiments. Figures S16-S21 show the other set of XPS spectra of all electrodes. The $\mathrm{O} 1 \mathrm{~s}$ peaks provide insightful information regarding surface species, see Figure S17. The peak at $529.9 \mathrm{eV}$ has been assigned to lattice oxygens. ${ }^{64,65}$ The shoulder that becomes the main peak in some cases on the highenergy side can be convoluted into three peaks at 530.5, 531.2, and $532.3 \mathrm{eV}$ due to hydroxy, peroxy, and coordinated water species, respectively, see Figure S17. ${ }^{64,65}$ The O 1s spectra of the electrode over FTO (reflects the electrode top surface) and ground samples (provide more internal surface) display clear differences, see Figures S17 and S18. Hydroxide, peroxide, and coordinated water peaks are generally enhanced in the internal surface of the electrodes. However, one must be careful using $\mathrm{O}$ $1 \mathrm{~s}$ regions, because carbonate and graphene oxide-type species that may be likely products of calcination also appear in this region. Therefore, we instead focused on the transition-metal $2 p$ regions, see Figure S16. Also note that the Mn 2p intensity increases by annealing the samples at higher temperatures, possibly indicating an enrichment of $\mathrm{Mn}$ species on the surface of $\mathrm{m}-\mathrm{MnCo}_{2} \mathrm{O}_{4}$ electrodes, see Figure $\mathrm{S} 19$. This correlates with the Tafel slope, which also increases upon annealing. Manganese-rich surfaces have higher Tafel slopes. ${ }^{39}$ The coordinated water and peroxide species increased the most in $\mathrm{m}-\mathrm{NiCo}_{2} \mathrm{O}_{4}$ electrodes after $\mathrm{CP}$ experiments, compare the spectra in Figure $\mathrm{S} 18$. The peak at around $531.5 \mathrm{eV}$ becomes the major peak in $\mathrm{m}-\mathrm{NiCo}_{2} \mathrm{O}_{4}-10-350$, which is the best-performing $\mathrm{m}-\mathrm{NiCo}_{2} \mathrm{O}_{4}$ electrode. The origin of enhancement of the peak at $531.5 \mathrm{eV}$ may be due to the formation of $\mathrm{NiOOH}$ and $\mathrm{Ni}(\mathrm{OH})_{2}$ species. Also, remember that the $\mathrm{m}-\mathrm{NiCo}_{2} \mathrm{O}_{4}$ electrode has an $\mathrm{NiO}$ side product that undergoes transformation to $\mathrm{NiO}-$ $\mathrm{NiOOH}$ and $\mathrm{NiO}-\mathrm{Ni}(\mathrm{OH})_{2}$ core-shell structures during the CP experiment. ${ }^{38}$ Note that the hydroxide species on both $\mathrm{NiOOH}$ and $\mathrm{Ni}(\mathrm{OH})_{2}$ are not terminal surface hydroxides (coordinated to one metal ion), instead they are coordinated to three $\mathrm{Ni}^{\mathrm{n}+}$ ions in layered $\mathrm{NiOOH}$ and $\mathrm{Ni}(\mathrm{OH})_{2}$. Therefore, the $\mathrm{O} 1 \mathrm{~s}$ peak appears at around $531.5 \mathrm{eV}$. The Ni 2 p spectra also corroborate this, see Figures $\mathrm{S} 16 \mathrm{~b}$ and $\mathrm{S} 20 \mathrm{~b}, \mathrm{~d}$. The peak at around $855.1 \mathrm{eV}$ is due to $\mathrm{Ni}^{2+}(\mathrm{NiO})$ that decreases over time during the $\mathrm{CP}$ experiment and the peak at around $856.3 \mathrm{eV}$ becomes the major peak after the $\mathrm{CP}$ experiment, indicating the enrichment of $\mathrm{Ni}^{2+} / \mathrm{Ni}^{3+}\left(\mathrm{Ni}(\mathrm{OH})_{2}\right.$ and $\left.\mathrm{NiOOH}\right)$ species at the surface. Clearly, from both $\mathrm{O} 1 \mathrm{~s}$ and $\mathrm{Ni} 2 \mathrm{p}$ regions, the surface of $\mathrm{m}-\mathrm{NiCo}_{2} \mathrm{O}_{4}$ changes after the $\mathrm{CP}$ experiments, compare spectra in Figure S16b and S20. Moreover, the changes in $\mathrm{m}-\mathrm{MnCo}_{2} \mathrm{O}_{4}$ in all regions, namely, $\mathrm{O} 1 \mathrm{~s}, \mathrm{Co} 2 \mathrm{p}$, and $\mathrm{Mn} 2 \mathrm{p}$ are quite small. The $\mathrm{Mn} 2 \mathrm{p}$ spectra display peaks due to $\mathrm{Mn}^{2+}, \mathrm{Mn}^{3+}$, and $\mathrm{Mn}^{4+}$ species, see Figure S16d. Overall, changes in the metal 2p spectra (other than $\mathrm{Ni} 2 \mathrm{p}$ ) are negligibly small, indicating the stability of the $\mathrm{m}-\mathrm{MnCo}_{2} \mathrm{O}_{4}$ electrode surfaces, as we predicted from the electrochemical analysis in the previous section. The Co $2 p$ region of all three electrodes (top surface and internal surface before and after use in CP experiments) was also recorded, as it is the other common element in three structures. Note that it is difficult to evaluate the oxidation state of cobalt (similarly for $\mathrm{Mn}$ and $\mathrm{Ni}$ ) due to the complexity of the $2 \mathrm{p}$ line shape, which consists of peaks from multiplet splittings ${ }^{66}$ (due to coupling between the unpaired $2 \mathrm{p}^{5}$ electron and unpaired valance electrons), oxidation states, and also overlapping of the satellite peaks. However, the satellite peaks of cobalt species are well resolved from the main peak and appears at $786 \mathrm{eV}$ for $\mathrm{Co}$ (II) and at $790 \mathrm{eV}$ for the $\mathrm{Co}$ (III) and Co(IV) species (see the Co $2 \mathrm{p}$ spectra in Figures S16a,c,e and S19-S21). Also note that it is an accepted practice to use the satellite peaks for determining the oxidation state of cobalt species. ${ }^{66}$ Based on this information, we can conclude that both the $\mathrm{m}-\mathrm{NiCo}_{2} \mathrm{O}_{4}$ and $\mathrm{m}-\mathrm{MnCo}_{2} \mathrm{O}_{4}$ surfaces contain both $\mathrm{Co}$ (II) and $\mathrm{Co}$ (III)/Co(IV) sides; however, in $\mathrm{m}-\mathrm{ZnCo}_{2} \mathrm{O}_{4}$, almost no $\mathrm{Co}$ (II) sides are detected. This is also clear from the $\mathrm{Zn} 2 \mathrm{p}$ region (Figure S21b,d) that displays simple $\mathrm{Zn}$ (II)-related peaks at 1021 and $1044 \mathrm{eV}$ due to ${ }^{2} \mathrm{P}_{3 / 2}$ and ${ }^{2} \mathrm{P}_{1 / 2}$ spin-orbital states, respectively. ${ }^{67}$ Since Co is in the $3+$ oxidation state in $\mathrm{m}-\mathrm{ZnCo}_{2} \mathrm{O}_{4}$, only the satellite peak that originates from the $\mathrm{Co}$ (III) side and the main ${ }^{2} \mathrm{P}_{3 / 2}$ peak become more symmetric, because $\mathrm{Co}(\mathrm{III})$ species with a $\mathrm{d}^{6}$ low-spin electron configuration (all valence electrons are paired) is not subjected to multiplet splitting. Detailed XPS analyses show that all metal species used in our proposal were detected and consistent with our mechanism.

We also evaluated the anodic charge-transfer coefficient $\left(\alpha_{\mathrm{a}}\right)$ of electrodes using Tafel slopes ( $A_{\mathrm{T}}$ values, where $A_{\mathrm{T}}=$ $2.303 R T /\left(n \alpha_{\mathrm{a}} F\right)=59.2 /\left(\mathrm{n} \alpha_{\mathrm{a}}\right), R$ is the gas constant, $T$ is the temperature, $n$ is the number of electron transferred, and $F$ is Faraday's constant) to support our proposal, see Table 3. It is a useful number for determining the rate-determining step in the OER process ${ }^{68,69}$ Since more than one electron transfer is unlikely in a single step, $n$ is considered to be one. ${ }^{68}$ Therefore, $\alpha_{\mathrm{a}}$ is equal to $59.2 / A_{\mathrm{T}}$. The charge-transfer coefficient of both m$\mathrm{NiCo}_{2} \mathrm{O}_{4}$ and $\mathrm{m}-\mathrm{ZnCo}_{2} \mathrm{O}_{4}$ electrodes is remarkably similar and around one. It means that the rate-determining step involves a chemical step after the first electron-transfer step in the OER process, ${ }^{69}$ as suggested in step 2 (see Figure 10a). However, the $\alpha_{\mathrm{a}}$ value gradually decreases from 0.95 (in m- $\mathrm{MnCo}_{2} \mathrm{O}_{4}-10-300$ ) up to 0.70 (in $\mathrm{m}-\mathrm{MnCo}_{2} \mathrm{O}_{4}-10-450$ ). Also note that in our previous work on mesoporous $\mathrm{LiMn}_{2} \mathrm{O}_{4}$, where both metals are manganese and are in 3+ and 4+ oxidation states, the Tafel slope is around $120 \mathrm{mV} / \mathrm{dec}$ with an $\alpha_{\mathrm{a}}$ value of 0.5 . As suggested by Doyl et al., ${ }^{69}$ the first electron-transfer step in a sequential reaction is the rate-determining step in the $\mathrm{m}-\mathrm{MnCo}_{2} \mathrm{O}_{4}$ electrodes. However, we have suggested the first electronreleasing step as the oxidation of $\mathrm{M}^{\prime}$ (II) to $\mathrm{M}^{\prime}$ (III) rather than the oxidation of $\mathrm{Mn}(\mathrm{IV})$ to $\mathrm{Mn}(\mathrm{V}){ }^{39}$ This was a reasonable suggestion as one would expect that the change of $\mathrm{M}^{2+}$ to $\mathrm{M}^{3+}$ would occur at a lower potential. However, if we consider the $\mathrm{M}^{\prime}(\mathrm{II})$ species as $\mathrm{M}^{\prime}(\mathrm{O})_{3}\left(\mathrm{OH}_{2}\right)_{3}$ and the $\mathrm{Mn}(\mathrm{IV})$ species as a tetrahedral $\left(\mathrm{O}=\mathrm{Mn}(\mathrm{O})_{3}\right)$ or octahedral $(\mathrm{O}=\mathrm{Mn}$ $\left.(\mathrm{O})_{3}\left(\mathrm{OH}_{2}\right)_{2}\right)$, Sanderson's electronegativity $(\chi)$ of likely surface species can be calculated from the geometric mean of electronegativity of the atomic constituents (such as $\chi_{\mathrm{M} x \mathrm{O} y}=$ $\left(\chi_{\mathrm{M}}{ }^{x} \chi_{\mathrm{O}}{ }^{y}\right)^{1 /(x+y)}$ for the $\mathrm{M}_{x} \mathrm{O}_{y}$ oxide, where $\chi_{\mathrm{M}}$ is the Mulliken electronegativity of the metal atom and $\chi_{\mathrm{O}}$ is that of the oxygen atom). Therefore, Sanderson's electronegativity of $\mathrm{O}=\mathrm{Mn}(\mathrm{O})_{3}$ is $5.96 \mathrm{eV}$ and that of $\left(\mathrm{O}=\mathrm{Mn}(\mathrm{O})_{3}\left(\mathrm{OH}_{2}\right)_{2}\right)$ is $6.82 \mathrm{eV} .{ }^{70}$ Note that the oxygens in the brackets are lattice oxygens and are shared by three metal ions. The electronegativity of $\mathrm{Co}\left(\mathrm{O}_{3}\right)$ $\left(\mathrm{OH}_{2}\right)_{3}$ side is $6.98 \mathrm{eV}$ [calculated from $\left(\chi_{\mathrm{Co}} \chi_{\mathrm{O}}^{4} \chi_{\mathrm{H}}^{6}\right)^{1 / 11}$, where $\chi_{\mathrm{Co}}$ is $4.30 \mathrm{eV}, \chi_{\mathrm{O}}$ is $7.54 \mathrm{eV}$, and $\chi_{\mathrm{H}}$ is $7.18 \mathrm{eV}$ ] and higher than that of $\mathrm{Mn}(\mathrm{IV})\left(\mathrm{O}=\mathrm{Mn}(\mathrm{O})_{3}\left(\mathrm{OH}_{2}\right)_{2}\right)$ species; therefore, it may require higher potential to oxidize compared to that of $\mathrm{Mn}^{4+}$ species over the electrode surface (electronegativity difference of at least $160 \mathrm{meV}$ ) to $\mathrm{Mn}^{5+}$. To clarify the above statements, we also show the 3D structure of the likely neutral, metal surface species in Figure S22. The electronegativity difference in both $\mathrm{NiCo}_{2} \mathrm{O}_{4}$ and $\mathrm{ZnCo}_{2} \mathrm{O}_{4}$ cases $\left(\mathrm{O}=\mathrm{Co}(\mathrm{O})_{3}\left(\mathrm{OH}_{2}\right)_{2}, 6.93 \mathrm{eV}\right.$, versus $\mathrm{Ni}\left(\mathrm{O}_{3}\right)\left(\mathrm{OH}_{2}\right)_{3}, 6.99 \mathrm{eV}$, and $\mathrm{O}=\mathrm{Co}(\mathrm{O})_{3}\left(\mathrm{OH}_{2}\right)_{2}$ versus $\mathrm{Co}\left(\mathrm{O}_{3}\right)\left(\mathrm{OH}_{2}\right)_{3}$, respectively) is only 60 and $50 \mathrm{meV}$, 
respectively. This difference could be further reduced in $\mathrm{m}$ $\mathrm{ZnCo}_{2} \mathrm{O}_{4}$ due to the $\mathrm{Zn}(\mathrm{II})$ ion, which is the most electronegative atom among all the four metals $(\chi$ values of $\mathrm{Mn}, \mathrm{Co}, \mathrm{Ni}$, and $\mathrm{Zn}$ are $3.72,4.30,4.40$, and $4.48 \mathrm{eV}$, respectively). Therefore, step 3 in our previous proposal may occur at a lower potential and may be considered as a second step rather than a third step. The corrected new mechanism is shown in Figure 10a. Also note that manganese can be oxidized to $5+$ or higher oxidation states and increases the rate of the chemical reaction (attack of hydroxide to oxo-oxygen over the surface to form the $\mathrm{O}-\mathrm{O}$ bond) in the second step and may be eliminated being part of the slow step in the OER to contribute to $A_{\mathrm{T}}$. However, in cobalt-modified $\mathrm{LiMn}_{2-x} \mathrm{Co}_{x} \mathrm{O}_{4},{ }^{39} \mathrm{~m}-\mathrm{NiCo}_{2} \mathrm{O}_{4}$, and $\mathrm{m}-\mathrm{ZnCo}_{2} \mathrm{O}_{4}$, the $\mathrm{Co}(\mathrm{IV})$ sides (tetrahedral $\mathrm{Co}(\mathrm{O})_{3}=\mathrm{O}$ or octahedral $\mathrm{O}=\mathrm{Co}(\mathrm{O})_{3}\left(\mathrm{OH}_{2}\right)_{2}$, see Figure 10a, step 2) are the active sides and are neutral, which may slow the chemical reaction and make it part of the rate-determining step. However, in $\mathrm{LiMn}_{2} \mathrm{O}_{4}$ and $\mathrm{m}-\mathrm{MnCo}_{2} \mathrm{O}_{4}$ (especially at higher calcination temperatures), the active sites are tetrahedral or octahedral manganese oxo and manganese oxo/cobalt oxo, respectively, over the electrode surface and influence the reaction mechanism of the OER process. Therefore, it is reasonable to suggest that the OER mechanism is changed or slightly modified in the $\mathrm{m}$ $\mathrm{MnCo}_{2} \mathrm{O}_{4}$ electrodes.

\section{CONCLUSIONS}

Two salt couples, namely, $\mathrm{Mn}(\mathrm{II}) / \mathrm{Co}(\mathrm{II}), \mathrm{Ni}(\mathrm{II}) / \mathrm{Co}(\mathrm{II})$, and $\mathrm{Zn}(\mathrm{II}) / \mathrm{Co}$ (II) nitrates, form a liquid crystalline mesophase with $\mathrm{C}_{12} \mathrm{E}_{10}$ and $\mathrm{P} 123$ in a broad range of salt/surfactant mole ratios in the presence of a charged surfactant, CTAB. CTAB stabilizes the LLCM at extremely high salt concentrations. The salt/ $\mathrm{C}_{12} \mathrm{E}_{10}$ mole ratio can be as high as 25 , but the mesophases are stable up to mole ratios of 8 and they leach out salt species at higher concentrations. The mesophases above mole ratios of 10 are metastable but can be prepared as fresh solutions and then upon coating over a substrate may be calcined immediately to form mesoporous metal cobaltites. Mesophases at 10 mole ratio of salts $/ \mathrm{C}_{12} \mathrm{E}_{10}$ and 60 mole ratio of salts/P123 are stable long enough to be prepared as thin gel films that can be calcined to form smooth thin films of metal cobaltites $\left(\mathrm{MCo}_{2} \mathrm{O}_{4}\right.$, where $\mathrm{M}$ is $\mathrm{Mn}, \mathrm{Ni}$, and $\mathrm{Zn}$ ). All three metal cobaltites form nano-crystalline pore walls at temperatures as low as $250{ }^{\circ} \mathrm{C}$; however, efficient surfactant burning occurs over $300{ }^{\circ} \mathrm{C}$. The pore walls are constructed from crystalline $\mathrm{MCo}_{2} \mathrm{O}_{4}$ nanoparticles that grow by annealing or directly calcining the films at higher temperatures, but $\mathrm{MnCo}_{2} \mathrm{O}_{4}$ resists high temperatures up to $550{ }^{\circ} \mathrm{C}$. Both $\mathrm{MnCo}_{2} \mathrm{O}_{4}$ and $\mathrm{ZnCo}_{2} \mathrm{O}_{4}$ films are pure without another crystalline phase; however, $\mathrm{NiCo}_{2} \mathrm{O}_{4}$ contains a $\mathrm{NiO}$ phase at elevated temperatures. The pore size, in both $\mathrm{NiCo}_{2} \mathrm{O}_{4}$ and $\mathrm{ZnCo}_{2} \mathrm{O}_{4}$ films, expands with increasing calcination/annealing temperatures, but the pores are more uniform with a smaller pore-size distribution in the $\mathrm{MnCo}_{2} \mathrm{O}_{4}$ films. The mesoporous $\mathrm{MCo}_{2} \mathrm{O}_{4}$ film can also be fabricated over FTO glasses and used as a WE in an alkaline solution for the OER. Typical CV curves of $\mathrm{MnCo}_{2} \mathrm{O}_{4}$ and $\mathrm{NiCo}_{2} \mathrm{O}_{4}$ display oxidation peaks due to manganese and cobalt and nickel and cobalt species, respectively, but the $\mathrm{CV}$ curve of $\mathrm{ZnCo}_{2} \mathrm{O}_{4}$ consists of a reversible peak due to oxidation/reduction of the $\mathrm{Co}^{3+} / \mathrm{Co}^{4+}$ couple, which is the only electroactive side for the OER process. The $\mathrm{m}-\mathrm{NiCo}_{2} \mathrm{O}_{4}$ and $\mathrm{m}-\mathrm{ZnCo}_{2} \mathrm{O}_{4}$ electrodes display similar Tafel slopes (around $60 \mathrm{mV} / \mathrm{dec}$ ). Overpotentials, required for the whole $\mathrm{m}-\mathrm{MCo}_{2} \mathrm{O}_{4}$ electrodes, occur around $200 \mathrm{mV}$ at 1 $\mathrm{mA} / \mathrm{cm}^{2}$ current density. This increases incrementally with increasing current density; however, the major overpotential is due to the high resistance (mostly originated from the FTO substrate) of the electrodes. This may be compensated by using a more conductive substrate in the fabrication of the electrodes. All electrodes are stable under harsh OER conditions with little changes in both $\mathrm{m}-\mathrm{MnCo}_{2} \mathrm{O}_{4}$ and $\mathrm{m}-\mathrm{ZnCo}_{2} \mathrm{O}_{4}$ electrodes and a significant but positive change in the $\mathrm{m}-\mathrm{NiCo}_{2} \mathrm{O}_{4}$ electrode. The $\mathrm{m}-\mathrm{NiCo}_{2} \mathrm{O}_{4}$ electrodes become better conductors over time in the long-run CP experiments. The OER mechanism is similar in $\mathrm{m}-\mathrm{NiCo}_{2} \mathrm{O}_{4}$ and $\mathrm{m}-\mathrm{ZnCo}_{2} \mathrm{O}_{4}$ electrodes but differs in the $\mathrm{m}$ $\mathrm{MnCo}_{2} \mathrm{O}_{4}$ electrode. Changes in the mechanism may be related to the electronegativity of the surface species, such that manganese needs to be at the $5+$ oxidation state for the OER process, and the positively charged $\mathrm{Mn}^{5+}$ side enhances the hydroxide concentration around the manganese-oxo side and increases the rate of hydroxide attack to the manganese-oxo side for the $\mathrm{O}-\mathrm{O}$ bond formation, immediately after the first electron transfer. This eliminates the slow chemical step (attack of hydroxide to metal-oxo) from being part of the ratedetermining step in the OER of the $\mathrm{m}-\mathrm{NiCo}_{2} \mathrm{O}_{4}$ and $\mathrm{m}$ $\mathrm{ZnCo}_{2} \mathrm{O}_{4}$ electrodes. Factors for producing efficient electrodes include the electrode stability, surface area, surface chemical composition, and crystallinity of the pore walls, and the $\mathrm{m}$ $\mathrm{MCo}_{2} \mathrm{O}_{4}$ thin-film electrodes satisfy all the abovementioned factors. Therefore, this research can be expanded along these lines by modifying the MASA process using other transitionmetal salts and/or polymerizing ingredients (such as tetraethylorthosilicate) and surface modification techniques.

\section{ASSOCIATED CONTENT}

\section{S1 Supporting Information}

The Supporting Information is available free of charge at https://pubs.acs.org/doi/10.1021/acsaem.1c00064.

Additional XPS spectra, small- and high-angle diffraction patterns, $\mathrm{N}_{2}$ adsorption-desorption data, SEM and TEM images, electrochemical data including CV curves, CPs, IV, and Tafel plots, and the content of solutions used in the synthesis (PDF)

\section{AUTHOR INFORMATION}

\section{Corresponding Author}

Ömer Dag - Department of Chemistry, Bilkent University, Ankara 06800, Turkey; UNAM冈National Nanotechnology Research Center and Institute of Materials Science and Nanotechnology, Bilkent University, Ankara 06800, Turkey; ำ orcid.org/0000-0002-1129-3246; Email: dag@ fen.bilkent.edu.tr

\section{Authors}

Assel Amirzhanova - Department of Chemistry, Bilkent University, Ankara 06800, Turkey

Nesibe Akmanşen - Department of Chemistry, Bilkent University, Ankara 06800, Turkey

Irmak Karakaya - Department of Chemistry, Bilkent University, Ankara 06800, Turkey

Complete contact information is available at:

https://pubs.acs.org/10.1021/acsaem.1c00064

\section{Author Contributions}

The manuscript was written through contributions of all authors. All authors have given approval to the final version of the manuscript. 


\section{Funding}

TÜBİTAK $118 Z 820$.

\section{Notes}

The authors declare no competing financial interest.

\section{ACKNOWLEDGMENTS}

The authors thank TÜBITAK (under the project number $118 \mathrm{Z} 820$ ) for the financial support of this work. Ö.D. is a member of the Science Academy, Istanbul, Turkey. The authors also thank Sina Sadigh Akbari and Prof. Ferdi Karadas for GC measurements.

\section{ABBREVIATIONS}

MASA, molten salt-assisted self-assembly;

OER, oxygen evolution reaction

$\mathrm{CP}$, chronopotentiometry

CA, chronoamperometry

BET, Brunauer-Emmett-Teller

$\mathrm{BJH}$, Barrett-Joyner-Halenda

\section{REFERENCES}

(1) Han, L.; Dong, S.; Wang, E. Transition-metal (Co, Ni, and Fe)based electrocatalysts for the water oxidation reaction. Adv. Mater. 2016, 28, 9266-9291.

(2) Walter, M. G.; Warren, E. L.; McKone, J. R.; Boettcher, S. W.; Mi, Q.; Santori, E. A.; Lewis, N. S. Solar water splitting cells. Chem. Rev. 2010, 110, 6446-6473.

(3) Grewe, T.; Deng, X.; Weidenthaler, C.; Schüth, F.; Tüysüz, H. Design of ordered mesoporous composite materials and their electrocatalytic activities for water oxidation. Chem. Mater. 2013, 25, 4926-4935.

(4) Wang, Y.; Zhou, T.; Jiang, K.; Da, P.; Peng, Z.; Tang, J.; Kong, B.; Cai, W.-B.; Yang, Z.; Zheng, G. Reduced mesoporous $\mathrm{Co}_{3} \mathrm{O}_{4}$ nanowires as efficient water oxidation electrocatalyst and supercapacitor electrodes. Adv. Energy Mater. 2014, 4, 1400696.

(5) Xu, L.; Jiang, Q.; Xiao, Z.; Li, X.; Huo, J.; Wang, S.; Dai, L. Plasmaengraved $\mathrm{Co}_{3} \mathrm{O}_{4}$ nanosheets with oxygen vacancies and high surface area for the oxygen evolution reaction. Angew. Chem., Int. Ed. 2016, 55, $5277-5281$.

(6) Brock, S. L.; Duan, N.; Tian, Z. R.; Giraldo, O.; Zhou, H.; Suib, S. L. A review of porous manganese oxide materials. Chem. Mater. 1998, $10,2619-2628$.

(7) Guo, Y.; Tang, J.; Qian, H.; Wang, Z.; Yamauchi, Y. One-pot synthesis of zeolitic imidazolate framework 67-derived hollow $\mathrm{Co}_{3} \mathrm{~S}_{4} @$ $\mathrm{MoS}_{2}$ heterostructures as efficient bifunctional catalysts. Chem. Mater. 2017, 29, 5566-5573.

(8) Guo, Y.; Tang, J.; Wang, Z.; Kang, Y.-M.; Bando, Y.; Yamauchi, Y. Elaborately assembled core-shell structured metal sulfides as a bifunctional catalyst for highly efficient electrochemical overall water splitting. Nano Energy 2018, 47, 494-502.

(9) Guo, Y.; Park, T.; Yi, J. W.; Henzie, J.; Kim, J.; Wang, Z.; Jiang, B.; Bando, Y.; Sugahara, Y.; Tang, J.; Yamauchi, Y. Nanoarchitectonics for transition-metal-sulfide-based electrocatalysts for water splitting. $A d v$. Mater. 2019, 31, 1807134.

(10) Uzunok, I.; Kim, J.; Çolak, T. O.; Kim, D. S.; Kim, H.; Kim, M.; Yamauchi, Y.; Dag, Ö. Lyotropic liquid crystalline mesophases made of salt-acid-surfactant systems for the synthesis of novel mesoporous lithium metal phosphates. ChemPlusChem 2019, 84, 1544-1553.

(11) Xiao, X.; Zou, L.; Pang, H.; Xu, Q. Synthesis of micro/nanoscaled metal-organic frameworks and their direct electrochemical applications. Chem. Soc. Rev. 2020, 49, 301-331.

(12) Tan, H.; Tang, J.; Henzie, J.; Li, Y.; Xu, X.; Chen, T.; Wang, Z.; Wang, J.; Ide, Y.; Bando, Y.; Yamauchi, Y. Assembly of hallow carbon nanospheres on graphene nanosheets and creation of iron-nitrogendoped porous carbon for oxygen reduction. ACS Nano 2018, 12, 56745683.
(13) Xia, W.; Tang, J.; Li, J.; Zhang, S.; Wu, K. C. W.; He, J.; Yamauchi, Y. Defect-rich graphene nanomesh produced by thermal exfoliation of metal-organic frameworks for oxygen reduction. Angew. Chem., Int. Ed. 2019, 58, 13354-13359.

(14) Guo, X.; Chen, C.; Zhang, Y.; Xu, Y.; Pang, H. The application of transition metal cobaltites in electrochemistry. Energy Storage Mater. 2019, 23, 439-465.

(15) Li, W.; Liu, J.; Zhao, D. Mesoporous materials for energy conversion and storage devices. Nat. Rev. Mater. 2016, 1, 16023.

(16) Chandrasekara, S.; Bowen, C.; Zhang, P.; Li, Z.; Yuan, Q.; Ren, $\mathrm{X}$.; Deng, L. Spinel photocatalysts for environmental remediation, hydrogen generation, $\mathrm{CO}_{2}$ reduction and photoelectrochemical water splitting. J. Mater. Chem. A 2008, 6, 11078-11104.

(17) Wang, W.; Kuai, L.; Cao, W.; Huttula, M.; Ollikkala, S.; Ahopelto, T.; Honkanen, A.-P.; Huotari, S.; Yu, M.; Geng, B. Massproduction of mesoporous $\mathrm{MnCo}_{2} \mathrm{O}_{4}$ spinels with manganese(IV)- and cobalt(II)-rich surface for superior bifunctional oxygen electrocatalysis. Angew. Chem., Int. Ed. 2017, 56, 14977-14981.

(18) Abidat, I.; Bouchenafa-Saib, N.; Habrioux, A.; Comminges, C.; Canaff, C.; Rousseau, J.; Napporn, T. W.; Dambournet, D.; Borkiewicz, O.; Kokoh, K. B. Electrochemically induced surface modification of mesoporous spinels $\left(\mathrm{Co}_{3} \mathrm{O}_{4-\delta}, \mathrm{MnCo}_{2} \mathrm{O}_{4-\delta}, \mathrm{NiCo}_{2} \mathrm{O}_{4-\delta}\right)$ as the origin of the OER activity and stability in alkaline medium. J. Mater. Chem. A 2015, 3, 17433-17444.

(19) Gao, X.; Zhang, H.; Li, Q.; Yu, X.; Hong, Z.; Zhang, X.; Liang, C.; Lin, Z. Hierarchical $\mathrm{NiCo}_{2} \mathrm{O}_{4}$ hallow microcuboids as bifunctional electrocatalyst for overall water-splitting. Angew. Chem., Int. Ed. 2016, $55,6290-6294$.

(20) Zhang, D.; Zhang, Y.; Li, X.; Luo, Y.; Huang, H.; Wang, J.; Chu, P. K. Self-assembly of mesoporous $\mathrm{ZnCo}_{2} \mathrm{O}_{4}$ nanomaterials: density functional theory calculation and flexible all-solid-state energy storage. J. Mater. Chem. A 2016, 4, 568-577.

(21) Hung, T.-F.; Mohamed, S. G.; Shen, C.-C.; Tsai, Y.-Q.; Chang, W.-S.; Liu, R.-S. Mesoporous $\mathrm{ZnCo}_{2} \mathrm{O}_{4}$ nanoflakes with bifunctional electrocatalytic activities toward efficiencies of rechargeable lithiumoxygen batteries in aprotic media. Nanoscale 2013, 5, 12115-12119.

(22) Kim, T. W.; Woo, M. A.; Regis, M.; Choi, K.-S. Electrochemical synthesis of spinel type $\mathrm{ZnCo}_{2} \mathrm{O}_{4}$ electrodes for use as oxygen evolution reaction catalyst. J. Phys. Chem. Lett. 2014, 5, 2370-2374.

(23) Gu, D.; Schüth, F. Synthesis of no-silicious mesoporous oxides. Chem. Soc. Rev. 2014, 43, 313-344.

(24) Li, C.; Han, X.; Cheng, F.; Hu, Y.; Chen, C.; Chen, J. Phase and composition controllable synthesis of cobalt manganese spinel nanoparticles towards efficient oxygen electrocatalysis. Nat. Commun. 2015, 6, 7345.

(25) Tian, B.; Liu, X.; Yang, H.; Xie, S.; Yu, C.; Tu, B.; Zhao, D. General synthesis of ordered crystallized metal oxide nanoarrays replicated by microwave-digested mesoporous silica. Adv. Mater. 2003, $15,1370-1374$.

(26) Rumplecker, A.; Kietz, F.; Salabas, E.; Schüth, F. Hard templating pathways for the synthesis of nanostructured porous $\mathrm{Co}_{3} \mathrm{O}_{4}$. Chem. Mater. 2007, 19, 485-496.

(27) Deng, X.; Chen, K.; Tüysüz, H. Protocol for nanocasting method: preparation of ordered mesoporous metal oxides. Chem. Mater. 2017, $29,40-52$.

(28) Petkovich, N. D.; Stein, A. Controlling macro- and mesostructures with hierarchical porosity through combined hard and soft templating. Chem. Soc. Rev. 2013, 42, 3721-3739.

(29) Ren, Y.; Ma, Z.; Bruce, P. G. Ordered mesoporous metal oxides: synthesis and applications. Chem. Soc. Rev. 2012, 41, 4909-4927.

(30) Wei, T.-Y.; Chen, C.-H.; Chien, H.-C.; Lu, S.-Y.; Hu, C.-C. A Cost-Effective Supercapacitor Material of Ultrahigh Specific Capacitances: Spinel Nickel Cobaltite Aerogels from an Epoxide-Driven SolGel Process. Adv. Mater. 2010, 22, 347-351.

(31) Zhang, G.; Lou, X. W. D. General solution growth of mesoporous $\mathrm{NiCo}_{2} \mathrm{O}_{4}$ nanosheets on various conductive substrates as highperformance electrodes for supercapacitors. Adv. Mater. 2013, 25, 976-979. 
(32) Kaneti, Y. V.; Salunkhe, R. R.; Wulan Septiani, N. L.; Young, C.; Jiang, X.; He, Y.-B.; Kang, Y.-M.; Sugahara, Y.; Yamauchi, Y. General template-free strategy for fabricating mesoporous two-dimensional mixed oxide nanosheets via self-deconstruction/reconstruction of monodispersed metal glycerate nanospheres. J. Mater. Chem. A 2018, 6, 5971-5983.

(33) Karakaya, C.; Türker, Y.; Albayrak, C.; Dag, Ö. Assembly of molten transition metal salt-surfactant in a confined space for the synthesis of mesoporous metal oxide-rich metal oxide-silica thin films. Chem. Mater. 2011, 23, 3062-3071.

(34) Karakaya, C.; Türker, Y.; Dag, Ö. Molten-salt-assisted selfassembly (MASA)-synthesis of mesoporous metal titanate-titania, metal sulfide-titania, and metal selenide-titania thin films. Adv. Funct. Mater. 2013, 23, 4002-4010.

(35) Avcı, C.; Aydınlı, A.; Tuna, Z.; Yavuz, Z.; Yamauchi, Y.; Suzuki, N.; Dag, Ö. Molten salt assisted self assembly (MASA): Synthesis of mesoporous metal titanate $\left(\mathrm{CoTiO}_{3}, \mathrm{MnTiO}_{3}\right.$, and $\left.\mathrm{Li}_{4} \mathrm{Ti}_{5} \mathrm{O}_{12}\right)$ thin films and monoliths. Chem. Mater. 2014, 26, 6050-6057.

(36) Saat, G.; Balci, F. M.; Alsaç, E. P.; Karadas, F.; Dag, Ö. Molten salt self-assembly: synthesis of mesoporous $\mathrm{LiCoO}_{2}$ and $\mathrm{LiMn}_{2} \mathrm{O}_{4}$ thin films and investigation of electrocatalytic water oxidation performance of lithium cobaltate. Small 2018, 14, 1701913.

(37) Balci, F. M.; Karakaya, I.; Alsaç, E. P.; Yaman, M. Y.; Saat, G.; Karadas, F.; Ülgüt, B.; Dag, Ö. Synthesis of mesoporous $\mathrm{LiMn}_{2} \mathrm{O}_{4}$ and $\mathrm{LiMn}_{2-\mathrm{x}} \mathrm{Co}_{\mathrm{x}} \mathrm{O}_{4}$ thin films using the MASA approach as efficient water oxidation electrocatalysts. J. Mater. Chem. A 2018, 6, 13925-13933.

(38) Amirzhanova, A.; Karakaya, I.; Uzundal, C. B.; Karaoğlu, G.; Karadas, F.; Ülgüt, B.; Dag, Ö. Synthesis and water oxidation electrocatalytic and electrochromic behaviours of mesoporous nickel oxide thin film electrodes. J. Mater. Chem. A 2019, 7, 22012-22020.

(39) Karakaya, I.; Karadas, F.; Ülgüt, B.; Dag, Ö. Modification of mesoporous $\mathrm{LiMn}_{2} \mathrm{O}_{4}$ and $\mathrm{LiMn}_{2-\mathrm{x}} \mathrm{Co}_{\mathrm{x}} \mathrm{O}_{4}$ by SILAR method for highly efficient water oxidation electrocatalysis. Adv. Mater. Technol. 2020, 5, 2000353.

(40) Çelik, Ö.; Dag, Ö. A new lyotropic liquid crystalline system: oligo(ethylene oxide) surfactants with $\left[\mathrm{M}\left(\mathrm{H}_{2} \mathrm{O}\right)_{n}\right] \mathrm{X}_{\mathrm{m}}$ transition metal complexes. Angew. Chem., Int. Ed. 2001, 40, 3800-3803.

(41) Albayrak, C.; Özkan, N.; Dag, Ö. Origin of lyotropic liquid crystalline mesophase formation and liquid crystalline to mesostructured solid transformation in the metal nitrate salt-surfactant systems. Langmuir 2011, 27, 870-873.

(42) Albayrak, C.; Soylu, A. M.; Dag, Ö. Lyotropic liquid crystalline mesophases of $\left[\mathrm{Zn}\left(\mathrm{H}_{2} \mathrm{O}\right)_{6}\right]\left(\mathrm{NO}_{3}\right)_{2}-\mathrm{C}_{12} \mathrm{EO}_{10}-\mathrm{CTAB}-\mathrm{H}_{2} \mathrm{O}$ and $[\mathrm{Zn}-$ $\left.\left(\mathrm{H}_{2} \mathrm{O}\right)_{6}\right]\left(\mathrm{NO}_{3}\right)_{2}-\mathrm{C}_{12} \mathrm{EO}_{10}-\mathrm{SDS}-\mathrm{H}_{2} \mathrm{O}$ systems. Langmuir 2008, 24, $10592-10595$.

(43) Mitchell, D. J.; Tiddy, G. J. T.; Waring, L.; Bostock, T.; McDonald, M. P. Phase behaviour of polyoxyethelene surfactants with water. Mesophase structures and partial miscibility (cloud points). J. Chem. Soc., Faraday Trans. 1 1983, 79, 975-1000.

(44) Dong, R.; Hao, J. Complex fluids of poly(oxyethylene) monoalkyl ether nonionic surfactants. Chem. Rev. 2010, 110, 49785022.

(45) Li, J.; Xiong, S.; Liu, Y.; Ju, Z.; Qian, Y. High electrochemical performance of monodisperse $\mathrm{NiCo}_{2} \mathrm{O}_{4}$ mesoporous microspheres as an anode material for Li-ion batteries. ACS Appl. Mater. Interfaces 2013, 5, 981-988.

(46) Thommes, M.; Kaneko, K.; Neimark, A. V.; Olivier, J. P.; Rodriguez-Reinoso, F.; Rouquerol, J.; Sing, K. S. W. Physisorption of gasses, with special reference to the evaluation of surface area and pore size distribution (IUPAC technical report). Pure Appl. Chem. 2015, 87, 1051-1069.

(47) Xu, W.; Lyu, F.; Bai, Y.; Gao, A.; Feng, J.; Cai, Z.; Yin, Y. Porous cobalt oxide nanoplates enriched with oxygen vacancies for oxygen evolution reaction. Nano Energy 2018, 43, 110-116.

(48) Li, J.; Chu, D.; Dong, H.; Baker, D. R.; Jiang, R. Boosted oxygen evolution reactivity by igniting double exchange interaction in spinel oxides. J. Am. Chem. Soc. 2020, 142, 50-54.

(49) Wang, H.-Y.; Hsu, Y.-Y.; Chen, R.; Chan, T.-S.; Chen, H. M.; Liu, B. $\mathrm{Ni}^{3+}$-Induced formation of active $\mathrm{NiOOH}$ on the spinel $\mathrm{Ni}$-Co oxide surface for efficient oxygen evolution reaction. Adv. Energy Mater. 2015, 5,1500091

(50) Kim, T. W.; Woo, M. A.; Regis, M.; Choi, K.-S. Electrochemical synthesis of spinel type $\mathrm{ZnCo}_{2} \mathrm{O}_{4}$ electrodes for use as oxygen evolution reaction catalysts. J. Phys. Chem. Lett. 2014, 5, 2370-2374.

(51) Rani, B. J.; Yuvakkumar, R.; Ravi, G.; Hong, S. I.; Velauthapillai, D.; Guduru, R. K.; Thambidurai, M.; Dang, C.; Al-Onazi, W. A.; AlMohaimeed, A. M. Electrochemical water splitting exploration of $\mathrm{MnCo}_{2} \mathrm{O}_{4}, \mathrm{NiCo}_{2} \mathrm{O}_{4}$ cobaltites. New J. Chem. 2020, 44, 17679-17692.

(52) Yu, M. Q.; Li, Y. H.; Yang, S.; Liu, P. F.; Pan, L. F.; Zhang, L.; Yang, H. G. $\mathrm{Mn}_{3} \mathrm{O}_{4}$ nano-octahedrons on $\mathrm{Ni}$ foam as an efficient threedimensional oxygen evolution electrocatalyst. J. Mater. Chem. A 2015, $3,14101-14104$.

(53) Aqueel Ahmed, A. T.; Hou, B.; Chavan, H. S.; Jo, Y.; Cho, S.; Kim, J.; Pawar, S. M.; Cha, S.; Inamdar, A. I.; Kim, H.; Im, H. Selfassembled nanostructured $\mathrm{CuCo}_{2} \mathrm{O}_{4}$ for electrochemical energy storage and the oxygen evolution reaction via morphology engineering. Small 2018, 14, 1800742.

(54) Li, M.; Xiong, Y.; Liu, X.; Bo, X.; Zhang, Y.; Han, C.; Guo, L. Facile synthesis of electrospun $\mathrm{MFe}_{2} \mathrm{O}_{4}(\mathrm{M}=\mathrm{Co}, \mathrm{Ni}, \mathrm{Cu}, \mathrm{Mn})$ spinel nanofibers with excellent electrocatalytic properties for oxygen evolution and hydrogen peroxide reduction. Nanoscale 2015, 7, 8920-8930.

(55) Liu, J.; Zhu, D.; Ling, T.; Vasileff, A.; Qiao, S.-Z. S- $\mathrm{NiFe}_{2} \mathrm{O}_{4}$ Ultra-small nanoparticle built nanosheets for efficient water splitting in alkaline and neutral pH. Nano Energy 2017, 40, 264-273.

(56) Al-Mamun, M.; Su, X.; Zhang, H.; Yin, H.; Liu, P.; Yang, H.; Wang, D.; Tang, Z.; Wang, Y.; Zhao, H. Strongly coupled $\mathrm{CoCr}_{2} \mathrm{O}_{4} /$ Carbon nanosheets as high performance electrocatalysts for oxygen evolution reaction. Small 2016, 12, 2866-2871.

(57) Tang, D.; Ben, L.; Sun, Y.; Chen, B.; Yang, Z.; Gu, L.; Huang, X. Electrochemical behaviour and surface structural change of $\mathrm{LiMn}_{2} \mathrm{O}_{4}$ charged to 5.1 V. J. Mater. Chem. A 2014, 2, 14519-14527.

(58) Yang, Y.; Wang, Y.; Xiong, Y.; Huang, X.; Shen, L.; Huang, R.; Wang, H.; Pastore, J. P.; Yu, S.-H.; Xiao, L.; Brock, J. D.; Zhuang, L.; Abruña, H. D. In-situ absorption spectroscopy of a synergistic Co-Mn oxide catalyst for the oxygen reduction reaction. J. Am. Chem. Soc. 2019, $141,1463-1466$.

(59) Wang, Y.; Yang, Y.; Jia, S.; Wang, X.; Lyu, K.; Peng, Y.; Zheng, H.; Wei, X.; Ren, H.; Xiao, L.; Wang, J.; Muller, D. A.; Abruna, H. D.; Wang, B. J.; Lu, J.; Zhuang, L. Synergistic Mn-Co catalyst outperforms Pt on high-rate oxygen reduction for alkaline polymer electrolyte fuel cells. Nat. Commun. 2019, 10, 1506.

(60) Zhang, M.; de Respinis, M.; Frei, H. Time-resolved observations of water oxidation intermediates on a cobalt oxide nanoparticle catalyst. Nat. Chem. 2014, 6, 362-367.

(61) Zandi, O.; Hamann, T. W. Determination of photoelectrochemical water oxidation intermediates on haematite electrode surfaces using operando infrared spectroscopy. Nat. Chem. 2016, 8, 778-783.

(62) Zahran, Z. N.; Mohamed, E. A.; Naruta, Y. Kinetics and mechanism of heterogeneous water oxidation by $\alpha-\mathrm{Mn}_{2} \mathrm{O}_{4}$ sintered on an FTO electrode. ACS Catal. 2016, 6, 4470-4476.

(63) Jin, K.; Seo, H.; Hayashi, T.; Balamurugan, M.; Jeong, D.; Go, Y. K.; Hong, J. S.; Cho, K. H.; Kakizaki, H.; Bonnet-Mercier, N.; Kim, M. G.; Kim, S. H.; Nakamura, R.; Nam, K. T. Mechanistic investigation of water oxidation catalyzed by uniform, assembled $\mathrm{MnO}$ nanoparticles. $J$. Am. Chem. Soc. 2017, 139, 2277-2285.

(64) Dupin, J.-C.; Gonbeau, D.; Vinatier, P.; Levasseur, A. Systematic XPS studies of metal oxides, hydroxides and peroxides. Phys. Chem. Chem. Phys. 2002, 2, 1319-1324.

(65) Nesbitt, H. W.; Banerjee, D. Interpretation of XPS Mn(2p) spectra of $\mathrm{Mn}$ oxyhydroxides and constraints on the mechanism of $\mathrm{MnO}_{2}$ precipitation. Am. Mineral. 1998, 83, 305-315.

(66) Biesinger, M. C.; Payne, B. P.; Grosvenor, A. P.; Lau, L. W. M.; Gerson, A. R.; Smart, R. S. C. Resolving surface chemical states in XPS analysis of first row transition metals, oxides and hydroxides: $\mathrm{Cr}, \mathrm{Mn}$, $\mathrm{Fe}, \mathrm{Co}$ and Ni. Appl. Surf. Sci. 2011, 257, 2717-2730.

(67) Biesinger, M. C.; Lau, L. W. M.; Gerson, A. R.; Smart, R. S. C. Resolving surface chemical states in XPS analysis of first row transition 
metals, oxides and hydroxides: Sc, Ti, V, Cu, and Zn. Appl. Surf. Sci. 2010, 257, 887-898.

(68) Guidelli, R.; Compton, R. G.; Feliu, J. M.; Gileadi, E.; Lipkowski, J.; Schmickler, W.; Trasatti, S. Defining the charge transfer coefficient in electrochemistry: An assessment (IUPAC technical report). Pure Appl. Chem. 2014, 86, 245-258.

(69) Doyle, R. L.; Godwin, I. J.; Brandon, M. P.; Lyons, M. E. G. Redox and electrochemical water splitting catalytic properties of hydrated metal oxide modified electrodes. Phys. Chem. Chem. Phys. 2013, 15, 13737-13783.

(70) Pearson, R. G. Absolute electronegativity and hardness: application to inorganic chemistry. Inorg. Chem. 1988, 27, 734-740. 